\title{
Does a Nucleated Crack Propagate?
}

\author{
K. Sadananda ${ }^{\mathrm{a}}$, A. Arcari ${ }^{\mathrm{a}^{*}}$, and A.K. Vasudevan ${ }^{\mathrm{a}}$ \\ ${ }^{a}$ Technical Data Analysis, Inc., 3190 Fairview Park Dr., 22042, Falls Church, VA \\ *corresponding author: $\underline{\text { aarcari@ } @ \text { tda-i.com }}$
}

\begin{abstract}
Conditions for propagation or non-propagation of an incipient crack from stress concentrations such as notches, holes, etc., are evaluated using elastic-plastic fracture mechanics methods and the Kitagawa-Takahashi diagram, hence linking smooth specimen behavior to fracture mechanics. The analysis differs from all other previous models which are either empirically based or assume that short crack growth behavior differs from that of long cracks due to crack closure or lack of it. It is shown that the stress intensity factor of an incipient crack decreases and then increases as it moves away from the internal stress field of a notch. Crack propagation is ensured only when the minimum is equal to or greater than the unique fatigue threshold for crack growth. Otherwise non-propagation conditions prevail. Equations are developed to establish the conditions for the minimum stress required for continuous propagation of the originated crack. It is shown that by analyzing published results on notch-fatigue that specimen failure occurs only if the applied stresses exceed the minimum stress required for crack propagation. Otherwise crack arrest occurs resulting in non-propagating cracks. The analysis can be readily used to determine the conditions for failure of a notched specimen if the elastic stress concentration factor, $\mathrm{k}_{\mathrm{t}}$, the notch-tip radius, $\rho$, and fatigue crack threshold, $K_{t h}$, for the material are known. The analysis, in principle, is applicable to all subcritical crack growth processes.
\end{abstract}




\section{Introduction}

\begin{tabular}{|c|c|c|c|}
\hline \multicolumn{4}{|c|}{ Nomenclature } \\
\hline$\sigma$ & Maximum or alternating stress in fatigue & K & Alternating stress intensity factor \\
\hline$\sigma_{\max }$ & Maximum applied stress in fatigue & $\mathrm{K}_{\max }$ & Maximum stress intensity factor \\
\hline$\Delta \sigma$ & Applied stress range in fatigue & $\Delta \mathrm{K}$ & Stress intensity range \\
\hline$\sigma_{f}$ & Fracture stress in tensile testing & $\mathrm{K}_{\mathrm{SC}}$ & $\begin{array}{l}\text { Stress intensity, either maximum or } \\
\text { Alternating, for a short crack starting at a } \\
\text { notch }\end{array}$ \\
\hline$\sigma_{0}$ & Alternating endurance stress in fatigue & $\mathrm{K}_{\text {th }}$ & $\begin{array}{l}\text { Stress intensity threshold value, either } \\
\text { maximum or alternating }\end{array}$ \\
\hline$\sigma_{\text {apl }}$ & Applied stress at a notch & $\rho$ & Notch root radius \\
\hline $\mathrm{k}_{\mathrm{t}}$ & Elastic stress concentration factor & $\mathrm{k}_{\mathrm{f}}$ & Elastic stress concentration factor in fatigue \\
\hline$\sigma_{\mathrm{N}}$ & Local stress at the notch root & $a_{c}$ & $\begin{array}{l}\text { Critical crack size from Kitagawa-Takahashi } \\
\text { diagram }\end{array}$ \\
\hline
\end{tabular}

From the prognostic point a fundamental question exists concerning whether an initiated or diagnosed crack can grow or not under the applied loads to cause failure of the component in service. Engineering components always have stress concentrations in one form or the other. Cracks being high energy defects nucleate always at some stress concentrations. Even in smooth specimens, the microstructural inhomogeneities with the associated deformationincompatibilities provide the necessary sources of stress concentrations. In some cases, the large grains with favorable orientations deform first, and these localized deformations help in the formation of stress concentrations causing crack nucleation and its growth. During fatigue, the localized deformations can cause the formation of protrusions, which are in-situ generated stress concentrations, where a crack can nucleate. Hence stress concentrations, either in-situ generated or pre-existing, provide the locus for the nucleation of cracks.

Crack initiation is difficult to define, since it is intimately related to the sensitivity of the detection techniques. By the time the cracks are observed, they might have grown long enough that in many cases the remnant life of such component becomes insignificant under applied loads. Hence, US Navy relays on the detection of a crack of a limiting size in the critical components as sufficient grounds for replacement of the component. On the other hand, there are times when a nucleated crack does not grow under the service loads, either due to the geometry of the component or the redistribution of loads in the structure. Hence it is important to define a methodology to study if and when a nucleated crack grows or gets arrested. This has been a subject of intense study, particularly the behavior of cracks nucleated at pre-existing stress concentrations ${ }^{(1)}$, which are common for many components in service.

The problem here is centered on the fact that the criteria for crack nucleation and its propagation differ in some cases, while they remain the same in others. The demarcation between the two is difficult, although it is very important for both diagnostics and prognostics purposes. It requires careful analysis of crack nucleation at a pre-existing stress concentration on one-side, and the 
growth kinetics of such nucleated crack on the other. Sometimes a crack nucleates but does not propagate. The study of propagating versus non-propagating cracks at various types of notches has been of great interest ${ }^{(2)}$. In many cases, a growing crack can become non-propagating if the conditions for its growth are not fully met. This results in the fatigue stress concentration factor, $\mathrm{k}_{\mathrm{f}}$, differing from the elastic stress concentration factor, $\mathrm{k}_{\mathrm{t}}$. Several phenomenological models ${ }^{(3-}$

${ }^{14)}$ have been developed to account or to quantify the variation of $\mathrm{k}_{\mathrm{f}}$ from $\mathrm{k}_{\mathrm{t}}$. Recent review by Yao, et $\mathrm{al}^{(15)}$ provides a summary analysis of different approaches used to address this problem. In essence, all of them are based on some empirical assumption, formulation or a concept. In this paper, we analyze using elastic-plastic fracture mechanics approach whether or not an incipient crack initiated at a stress concentration propagates, as the answer is important for the purpose of prognostics.

\section{Background}

\subsection{The Griffith's Crack}

We have recently ${ }^{(16)}$ shown that for a crack to initiate and grow, not only the stress magnitude but its gradient is also important. This is illustrated schematically in Fig.1, as the Griffith's condition (shown in log-log coordinates). The stress to initiate a crack of size $a$, for an elastic case, is given by ${ }^{(17)}$,

$$
\sigma=\sqrt{(2 E \gamma / \pi a)}---------(1),
$$

where $\mathrm{E}$ is the elastic modulus, and $\gamma$ is surface energy. The straight line in Fig. 1a represents the Griffith's line. While the Griffith-condition is well known, the following important observations which are not very obvious can be made that are relavent for our subsequent analysis. a) Careful examination of the Fig.1a indicates that in additon to the magnitude, the stress gradient represented by the line has to be maintained for an incipient crack intiated to grow continously maintaining the Griffith's condition. Such a stress-gradient results in quasi-static subcritical crack growth, maintaining the Griffith's condition as it grows. Most importantly, if the stress gradient falls below the Griffith's condition at any time, then the growing crack becomes a nonpropagating crack. Similarly, if the stresses are above the Griffith's line, then the initiated crack accelarates. In the case of an elastic crack, if stresses fall below the line then the crack may stop growing unless the enviroment contaminating the freshly formed crack-surface prevents it. The minimum stress gradinent for continous propagation, therefore, is given by

$$
(d \sigma / d a)=-(1 / 2 a)(\sqrt{2 E \gamma / \pi a})
$$

Thus, Eqs. 1 and 2 determine the magnitude and gradient of the stress required for continous growth of an elastic-crack. The slope, for the elastic case in Fig. 1a, is (- 0.5). Conversely, when the slope is -0.5 in the $\log (\sigma)-\log$ (crack length) plot, the elastic or close to elastic conditions are 
said to be prevailing at the crack tip. For an elastic case, the material resistance is represented by the surface energy term, $\gamma$ and the elastic moduls, E.

b) As the crack size decreases, the applied stresses need to sustain the crack approaches infinity, as indicated by Eq. 1. Since the materials cannot sustain such high stresses, they undergo localized plastic deformation, thereby generating local stress concentrations. We call these stresses as internal stresses; and they average out across the specimen thickness to zero to keep the specimen in equilibrium. Hence, crack initiation in a finite specimen occurs at some local stress concentration which may be in-situ generated, while the nominal stress approaching the tensile strength or fracture strength of the specimen. For the purpose of illustration, this is shown schematically in Fig. 1b. It shows that the Griffith condition for a finite specimen deviates from the theoretical value as the crack length a approaches zero. Note that the curve deviates from the straight line to meet the fracture stress of the specimen. Since Griffith's condition is not met during that deviation, the local stress concentration has to exit compensating the applied stress to arrive at the Griffith's condition, in that regime. The local stress over and above the nominal stress, $\sigma_{\mathrm{f}}$, has to be such that the total stress in terms of its magnitude and gradient is given by Griffith's line. This becomes the minimum reqirement for the nucleation and propagation of the crack in that regime. Here, we are not bypassing the Griffith's condition, but meeting it by the sum of local and global stresses. Anytime the sum falls below the Griffith's line, then that initiated crack gets arrested. The triangle $\mathrm{ABC}$ defines the internal stress magnitude and the gradient required at local stress concentration. At point $\mathrm{C}$, Fig.1b, the remote stresses are reasonable enough to propagate the crack, without further aid from the local internal stresses. The crack will propagate at quasi-static conditon if the remote stress decreases along the Griffith's line, and will accelerate if the stresses are above the Griffith's line. Non-propagating condition remains the same. Thus Griffth's line defines the mininum stress and gradient required for continuous crack propagation, and hence the specimen failure. Hence any failure stress should be at or above the Griffith's line.

c) Finally, the deviation from the straight line in Fig. 1b, that is the stress bending towards $\sigma_{\mathrm{f}}$ limit, occurs naturally as the in-built local stresses aid the remote stresses in the nucleation and propagation of a crack. This deviation, therefore, is not due to some spurious effects such as the presence or the absence of crack closure during short-crack growth, or that short cracks behave differently from long cracks. The deviation occurs due to local deformations since the stress to initiate plastic flow is less than that needed to initiate a crack. Hence, other than the fact that the local and remote stresses together are operating in controlling the kinetics of crack initiation and growth, there is no failure of similutude for short cracks, as has been assumed in the literature ${ }^{(17)}$. In essence, Eqs. 1 and 2 still operate other than the fact that one has to consider the combined stresses. 


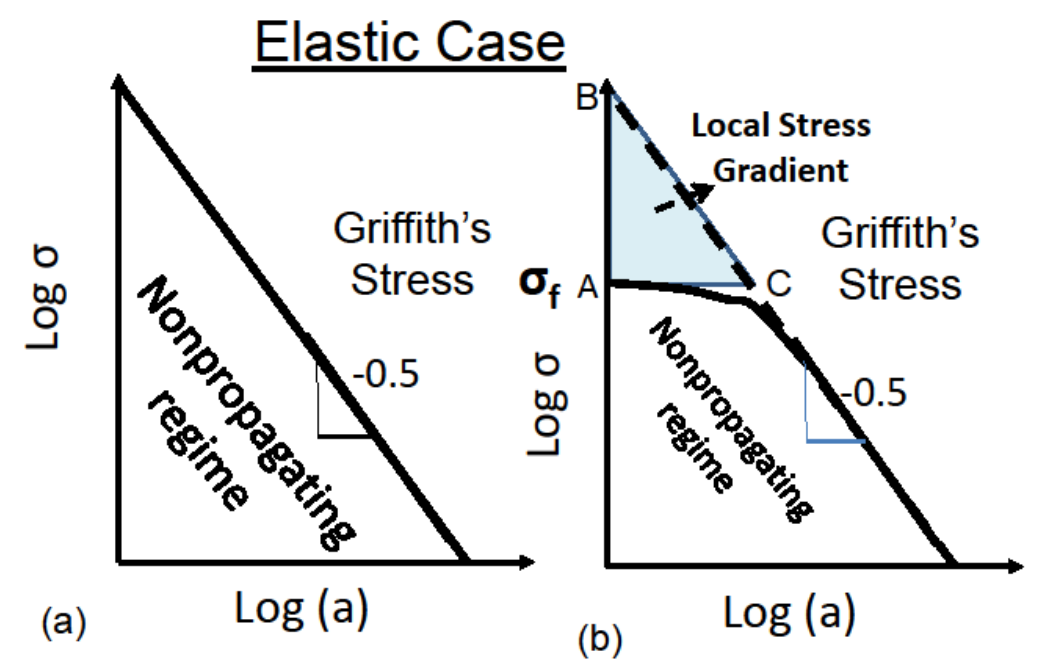

Figure 1: Crack initiation and Growth conditions for an elastic case a) Ideal case b) Finite specimen.

\subsection{Fatigue damage}

While considering fatigue damage, it is important to recognzie that cyclic loads require two parameters for unambigious description. This is emphasized since normally only amplitude is specified ignoring the maximum stress. Mean stress is known to affect the fatigue failure, since Goodman some 100+ years ago. Observed R-ratio effects, therefore, can be intrinsic to fatigue, even though R-ratio is not a suitable load parameter. There is no threshold in terms of R-ratio required for fatigue. After careful consideration, we came to the conclusion that maximum load and amplitude provide the clear parametric description to characterize fatigue damage, instead of amplitude and mean stress or amplitude and R-ratio ${ }^{(18)}$. This is schematically illustrated in Fig. 2 where amplitude and the maximum stress are needed to characterize fatigue damage. In the S-N curves of smooth specimen or crack growth rates in the fracture mechanics specimen, the two load parameters manifest in terms of $\Delta \sigma$ and $\sigma_{\max }$ for smooth specimen, and $\Delta K$ and $K_{\max }$ for fracture mechanics specimen. Experimental data follow L-shaped curves defining two liming conditions in terms of peak stress and amplitude. For example, for a fracture mechanics specimen, the threshold is not a single value but a curve, defining two limiing thresholds which are material-environment dependent properties. Similarly, there are two limiting endurance limits to be specified. Environment can affect both values, and thus the whole curve. For the current discussion, it is important to recognize that the R-ratio effects arise due to intrinsic nature of fatigue damage, and not due to some crack closure or lack of it, as has been assumed in the literature. Similarly, for a smooth specimen one has to consider not only the amplitude but also the role of $\sigma_{\max }$. These aspects become important in establishing the connection between the behavior of a smooth specimen on one end and a frature mechanics specimen on the other end, as is being done in Kitagawa-Takahashi diagram ${ }^{(19)}$. The notched-specimen falls in between two 
cases, approaching the smooth specimen behavior for low $\mathrm{k}_{\mathrm{t}}$ and behavior of a fracture mechanics specimen at high $\mathrm{k}_{\mathrm{t}}$. For the purpose of illustration, Fig. 3 shows the behavior of a smooth specimen showing the two-parameteric nature of fatigue in Ti-6Al-4V alloy ${ }^{(20)}$, the limiting values in terms of $\sigma_{\max }$ and $\Delta \sigma, \sigma_{\max -\mathrm{e}}$ and $\Delta \sigma_{\mathrm{e}}$. Other materials also should behave in the same way, although such extensive data are not available for analysis. Analysis of fatigue crack growth behavior in terms of $\Delta \mathrm{K}-\mathrm{K}_{\max }$ has been presented before for many alloys ${ }^{(21)}$.

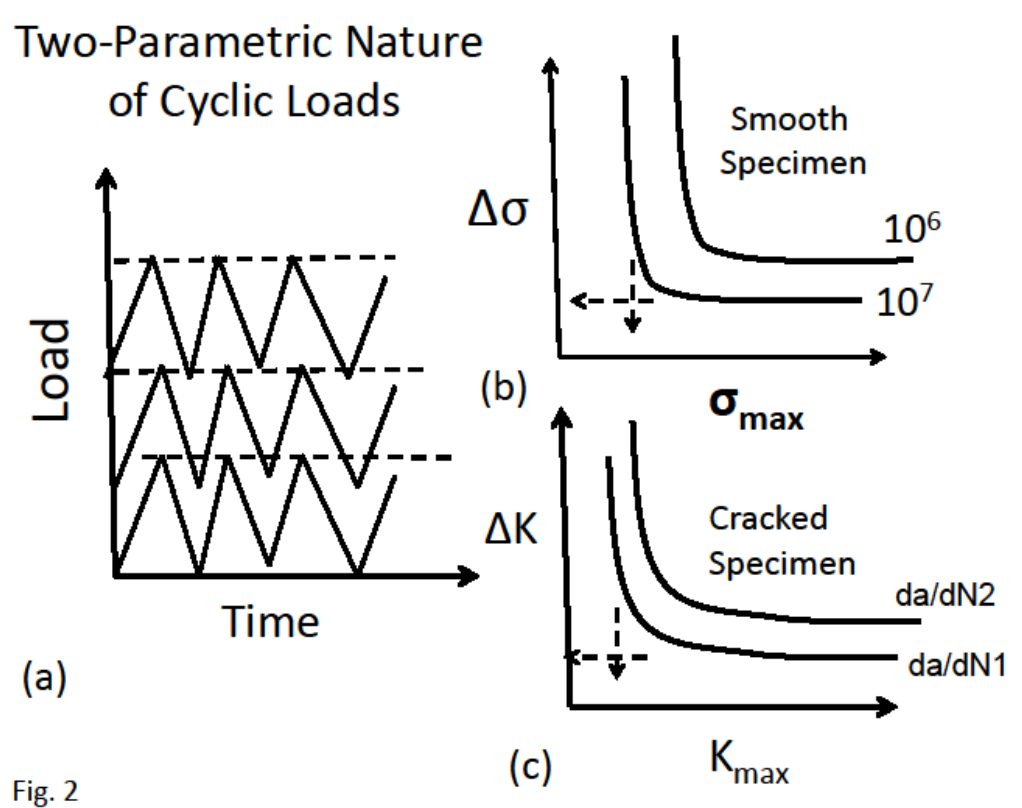

Figure 2: Fatigue requires two load parameters a) amplitude and maximum stress, resulting in L-shaped curves for a given number of cycles to failure or crack growth rate. Hence a) endurance is a curve with limiting $\sigma_{\max }$ and $\Delta \sigma$ and c) crack growth thresholds with limiting $\mathrm{K}_{\mathrm{max}, \text { th }}$ and $\Delta \mathrm{K}_{\mathrm{th}}$. 


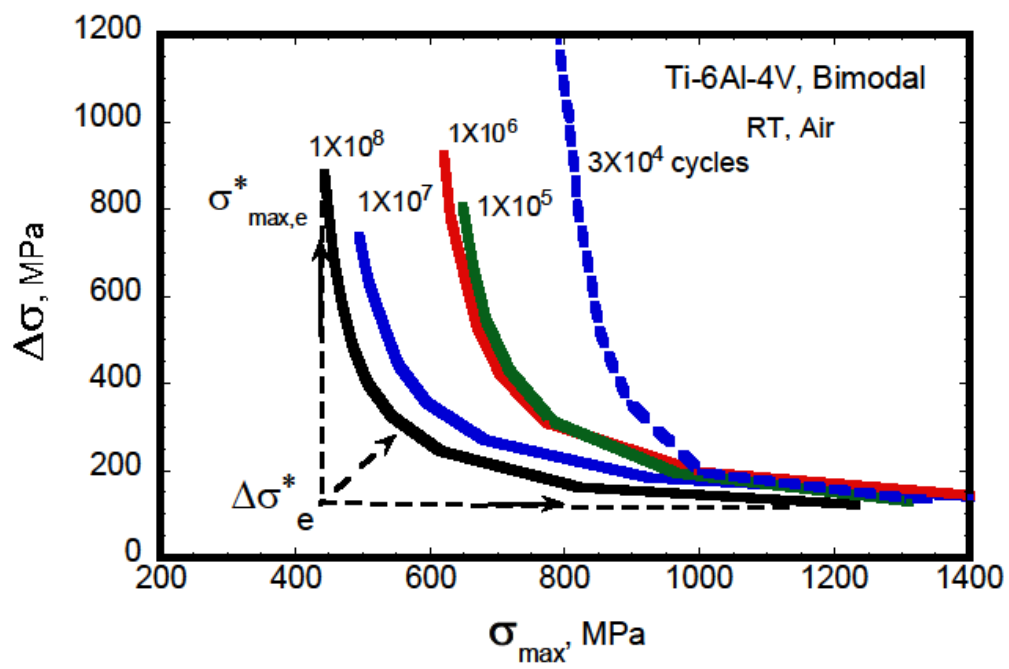

Figure 3: Fatigue S-N data of Ti-6Al-4V re-plotted in terms of $\Delta \sigma-\sigma_{\max }$ showing the L-shaped behavior.

In essence, the above background is provided to recognize a) analysis of fatigue damage requires two load or stress parameters, b) since R-ratio dependence is intrinisc to fatigue and manifests in terms of the variation of $\Delta \sigma$ and $\sigma_{\max }$ and $\Delta \mathrm{K}$ and $\mathrm{K}_{\max }$, any notch analysis should consider R-ratio effects,c) in addition to magnitude of stresses, their gradients are also important as they govern the initiation and growth of a crack, d) the behavior of short cracks is not much different from that of long cracks as the same thresholds are applicable, e) deviation observed for short crack behavior from that of long cracks arises as the material curcumvents the high stresses required to sustain short cracks. This is accomplished by localized internal streses arising from either pre-existing stress concentrations or in-situ generated stress concentrations or a combination of the two, f) Observed -0.5 slope in the $\log (\sigma)$ vs $\log$ (crack length) is an indication of the validity of linear elastic behaviour, even though from physical considerations at micro level, the fatigue damage itself involves localized irreversible plasticity. With this background we will examine the fatigue behavior of notched samples in relation to the that of smooth and fracture mechanics specimens.

\section{Analysis of fatigue failures in Notched Specimens}

Assessment of fatigue life of components with notches and other stress concentrations using the smooth specimen data has received lot of attention for the past few decades, because of its importance. The augumented stresses at the notches are localized and reduce to zero away from the notch tip $^{(22)}$. We call them internal stresses to differentiate them from the far-field or nominal stresses across the specimen thickness. For a smooth specimen they are the same as the applied stresses. The elastic stress concentration factor, $\mathrm{k}_{\mathrm{t}}$, defined as the ratio of the local stress at the notch root, $\sigma_{\mathrm{N}}$, to nominal stress, $\sigma$, may provide the necessary stress for the nucleation of the 
crack near the notch tip, but not for its propagation. For propagation, as discussed above, the stress gradients also have to be satisfied. When $\mathrm{k}_{\mathrm{t}}$ is large the gradients can be too sharp. Even for holes, where $\mathrm{k}_{\mathrm{t}}$ remains the same $(\approx 3)$, the fatigue life varies with the size of the hole ${ }^{(23,24)}$, since the range of internal stresses are proportional to the hole-radius. A fatigue notch factor, $\mathrm{k}_{\mathrm{f}}$, defined as the ratio of endurance limit of smooth specimen to that of a notched specimen, $\Delta \sigma_{0} / \Delta \sigma_{\mathrm{N}}$, differs from $\mathrm{k}_{\mathrm{t}}$.

Many empirical equations have been developed relating $\mathrm{k}_{\mathrm{f}}$ to $\mathrm{k}_{\mathrm{t}}$. The relation, in a general form, is expressed as

$k_{f}=f\left(k_{t}, \rho, \alpha\right)---------(3)$,

where $\rho$ is the notch root radius, and $\alpha$ is a material constant. Functional relation between $\mathrm{k}_{\mathrm{t}}$ and $\mathrm{k}_{\mathrm{f}}$ has been established empirically based on experimental data for different materials; the reliability of which is always questionable since predictions are often inaccurate. An empirical notch sensitivity factor has been introduced to characterize the notch sensitity of materials to notches as

$q=\left(k_{f}-1\right) /\left(k_{t}-1\right)^{---------(4)}$

where $\mathrm{q}$ varies from 0 to 1 , with $\mathrm{q}=1$ when $\mathrm{k}_{\mathrm{t}}=\mathrm{k}_{\mathrm{f}}$, and $\mathrm{q}=0$ when $\mathrm{k}_{\mathrm{f}}=1$.

Yao et $\mathrm{al}^{(15)}$ have provided a comprehensive review of the various expressions developed in the literature relating $\mathrm{k}_{\mathrm{f}}$ to $\mathrm{k}_{\mathrm{t}}$. They classify the expressions into three types, based on the basic assumptions made. They list as a) average stress models, b) stress field intensity models and c) fracture mechanics models.

In the average stress models, the average internal stress ahead of a notch is equated to the smooth specimen endurance stress for failure ${ }^{(13)}$. This average is computed differently in different models. Different approaches and fitting parameters are used in order to fit the experimental data in different materials.

In the stress-field intensity models, the accumulation of damage in the region covering several grains ahead of the notch tip is related to the fatigue damage in a smooth specimen. Damage is determined based on the microstrucal observations. Thus material response is incorporated into the models, in some form. In essence, not only the peak stress at the notch tip but the internal stress range in some form is incorporated into the fatigue life prediction. The exact relationships assumed in terms of damage in the smooth specimen and that in various notch-specimens vary in each model.

Fracture mechanics approaches, on the other hand, relate the behavior of short cracks to that of long cracks, again involving some assumptions. Since crack initiation and growth are involved in 
terms of fatigue, we resort here to the fracture mechanics approach in relating the fatigue failures in various types of notched specimens to that of a smooth specimen. The approach differs from all others since no specific assumptions are made for the description of short crack growth behavior.

\subsection{Fracture Mechanics Approach}

The basis for this approach rests in the classical paper by Kitagawa and Takahashi ${ }^{(19)}$ that relates the endurance limit of a smooth specimen to threshold crack growth behavior in a fracture mechanics specimen. A modified version of this is shown in Fig. 4. The authors showed that for specimens with very small cracks of less that $a_{c}$ or pre-existing stress concentrations, the endurance limit is close to that of a smooth specimen. For crack lengths greater than $a_{c}$ the data merged with that of fracture mechanics specimen. Thus the data merged with the thershold curve shown in Fig. 4 as it represents the threshold for crack propagation. We have recently modified the diagram extending the threshold line to beyond $a_{c}$; again, at very high stresses the line may join the smooth specimen fracture stress, $\sigma_{\mathrm{f}}$. The analogy with Fig. $1 \mathrm{~b}$ is obvious. This figure forms the basis for relating the behaviors of smooth and notched specimens on one side and fracture mechanics specimen on the other, thus covering the whole spectrum of material behavior.

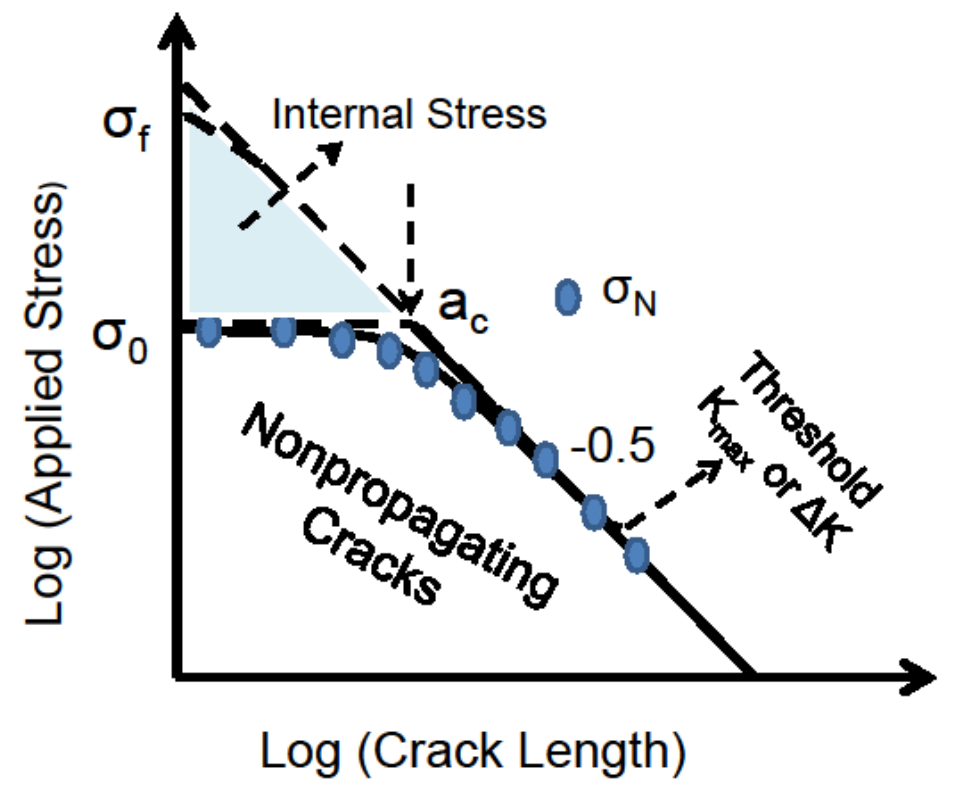

Figure 4: Original and the modified Kitagawa-Takahashi diagram.

Starting from El Haddad et $\mathrm{al}^{(9,10)}$, several approaches have been made in the literature in relating the crack initiation and growth in smooth and notched specimens to the growth in fracture mechanics specimen. These include an arbitrary addition of crack length $a_{c}$ as El Haddad et al. have done, to invocation of the brakedown of similitude for short cracks. The brakedown has been attributed to crack closure or more accurately to the lack of it. In essence, the long cracks 
have crack closure due to plastic zone in the crack-wake, while it is lacking in growing short cracks, as the steady-state conditions have not yet been established. The R-ratio behavior and many other fatigue related phenomena have been accounted on the basis of this crack closure concept. We have shown, however, that plasticity originated from the crack cannot close that crack $^{(25)}$, since it opens the crack while other forms of closure may occur, but their contribution is minimal. The material behavior, originally attributed to crack closure, can easily be accounted for by recognizing that fatigue involes two-load parameters, for correct description, as discussed with reference to Fig. 2.

In particular, for the smooth specimen to fail at $\sigma_{0}$, fatigue damage has to occur which generates dislocation structures, localized slip bands and the resulting intrusions and extrusions that provide the local stress concentrations, and more importantly the associated internal stresses that aid the applied stresses. Thus the crack initiation and propagation occur when the total stress due to the sum of the applied and internal stressses meet the threholds stress for crack initiation and growth. Hence, we have presened a modified Kitagawa-Takahashi diagram ${ }^{(26)}$ and in the process accounted for the behavoir of all short cracks that hither to have been accounted by the crack closure concept. In the same spirit, we will examine the behavior of notched spcimens in terms of crack nucleation and growth under elastic-plastic conditions, and relate it to the smooth specimen behavior. Thus, in contrast to all other papers in this area, we do not make any specific assumptions to account for the notch-specimen behavior in relation to the smooth specimen behavior, other than using Kitagawa-Takahashi results based on experimental verifications. Thus, equations relating $\mathrm{k}_{\mathrm{f}}$ to $\mathrm{k}_{\mathrm{t}}$ (Eg. 3) are develped here that are applicable for all stress concentrations and for all materials. For simplicity the problem here is limited to a twodimensional case, while the analysis for 3-D case is currently underway.

\subsection{Crack growth in Notch tip Stress-Fields}

The growth of a short crack in a notch tip stress field under elastic-plastic condition has been analyzed before, for various $\mathrm{k}_{\mathrm{t}}$ values and notch tip radii ${ }^{(26)}$. It was shown that depending on the $\mathrm{k}_{\mathrm{t}}$ value and root radius, $\rho$, the stress-intensity of a short crack increases sharply and then decreases and reachs a minimum before it increase again due to the nominal stresses present. Up to the minimum the internal stresses of the notch are dominating while beyond the minimum the nominal stresses will be controlling the crack growth. If the stress intensity factor for the short crack, $\mathrm{K}_{\mathrm{SC}}$ at the minimum falls below the threshold stress intensity for fatigue crack growth, the initiated crack gets arrested and becomes a nonpropagating crack. This is shown schematically in Fig. 5. Fig 5a describes the notch-tip stress fields that decrease to nominal stress far away from the notch, and Fig. $5 \mathrm{~b}$ shows the $\mathrm{K}_{\mathrm{sc}}$ variation as it grows away from the notch. As the crack length increases beyond the minimum, the nominal stresses will control the crack growth and the behavior reduces to that of a long crack, as the contribution from the internal stresses from the notch decreases to zero. 


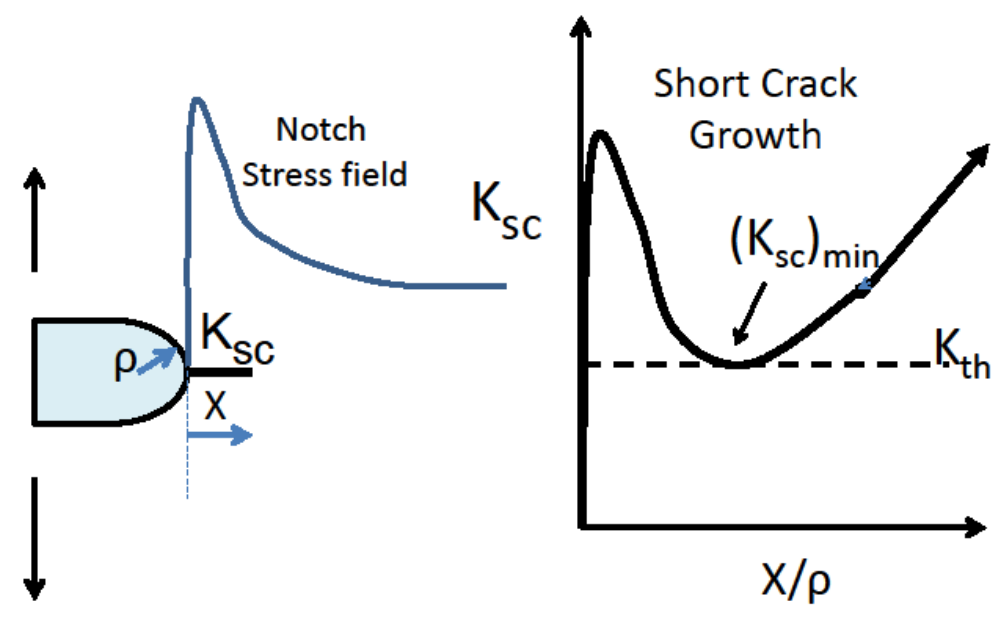

Figure 5: a) Growth of a short crack under notch tip stress fields b) Stress intensity factor of short crack with its decreasing and increasing value as it grows away from the notch tip.

The analysis ${ }^{(26)}$ shows that $\mathrm{K}_{\mathrm{sc}}$ at the minimum follows a simple relationship with $\mathrm{k}_{\mathrm{t}}$ and root radius, $\rho$. Considering various types of notches including holes, we have shown that the $\left(\mathrm{K}_{\mathrm{SC}}\right)_{\min }$ can be expessed as

$$
\left(\mathrm{K}_{\mathrm{SC}}\right)_{\min }=\left(\sigma_{\text {apl }}\right)\left[(\vee \rho)\left(\mathrm{k}_{\mathrm{t}}\right)^{1.3}\right] / 2------(5)
$$

For crack growth to be continuous, this minimum should be equal to or greater than the material threshold. Unlike what has been assumed in the literature, the fatigue thresholds do not depend on crack length for short cracks. Hence we can simply relate the $\left(\mathrm{K}_{\mathrm{sc}}\right)$ to crack growth threshold which is a material-environment dependent parameter. Crack growth condition, therefore, can be simply expressed as

$$
\left(\mathrm{K}_{\mathrm{SC}}\right)_{\min }=\left\{\left(\sigma_{\mathrm{apl}}\right)\left[\left(\vee_{\rho}\right)\left(\mathrm{k}_{\mathrm{t}}\right)^{1.3}\right] / 2\right\} \geq \mathrm{K}_{\mathrm{th}} \quad---(6),
$$

Where, $\mathrm{K}_{\mathrm{th}}$ is fatigue threshold, and depends only on the material in a given environment. While threshold is really a curve, Fig. 2c, we use for the analysis below experimental threshold value for a given R-ratio, matching the experiments on endurance tests for the same R-ratio. Rearranging the terms we have

$$
\sigma_{\text {apl }} \geq\left\{2 K_{\text {th }} /\left[(\vee \rho)\left(k_{t}\right)^{1.3}\right]\right\}
$$

Eq. 7 can be used to define the fatigue strength of a notch-specimen, where $\sigma_{\text {apl, }}$ corresponds to the endurance limit of the specimen. Eq. 7 shows that it is related to $\mathrm{k}_{\mathrm{t}}, \rho$, and $\mathrm{K}_{\mathrm{th}}$ following the functional relation stated in Eq. 3. Here, the material property corresponds to the threshold for fatigue crack growth while the rest vary with a given specimen geometry. If the fatigue thresholds and endurance limits are provided for a given R-ratio then the equation is valid for that R-ratio. The accuracy of the assessment depends on the accuracy of the threshold value, 
since the rest of the parameters are geometry dependent. The notch fatigue limit expressed as applied alternating stress at a notch, $\sigma_{\text {apl }}$, is related to the minimum (threshold) stress related to crack propagation.

The da/dN curves of materials normally show that with increasing crack growth rate the required stress intensity value increases beyond the threshold and approaches the overload fracture stress, $\mathrm{K}_{\mathrm{IC}}$. Hence, not only crack growth but specimen failure is also insured if we replace the $\mathrm{K}_{\text {th }}$ value in the above equation with the material $\mathrm{K}_{\mathrm{IC}}$ value under fatigue. For the current analysis, we limit our discussion to the minimum $\mathrm{K}$ required to initiate continuous crack growth.

We may note also that the analysis applies to all subcritical crack growth, since no assumption is made about cyclic loads, other than the fact that two stress variables are involved in fatigue. In principle, Kitagawa-Takahashi diagram is applicable for all subcritical crack growth as we have shown recently for stress-corrosion crack growth. For stress corrosion crack growth, Eq. 7 reduces to

$\sigma_{\text {apl }}=\sigma_{\mathrm{N}} \geq\left\{2 \mathrm{~K}_{\mathrm{ISCC}} /\left[(\vee \rho)\left(\mathrm{k}_{\mathrm{t}}\right)^{1.3}\right]\right\}$

where fatigue threshold is replaced by the $\mathrm{K}_{\text {Iscc }}$ for corrosion. Similarly, the equation can be applied to any other subcritical crack growth processes by substituting with the appropriate threshold value for crack growth.

Similarly, $\mathrm{k}_{\mathrm{f}}$ can be related to $\mathrm{k}_{\mathrm{t}} \mathrm{using}$ the above relation. It is given by

$\mathrm{k}_{\mathrm{f}}=\sigma_{0} / \sigma_{\mathrm{N}}=\left\{\left(\mathrm{k}_{\mathrm{t}}^{1.3} / \mathrm{Y}\right)\left[{ }^{\rho} /\left(4 \pi \mathrm{a}_{\mathrm{c}}\right)\right]\right\}$

Where $\mathrm{Y}$ is the compliance relation for a given geometry of the specimen, and $\mathrm{a}_{\mathrm{c}}$ is the critical crack size given by the Kitagawa diagram, Fig. 4. In terms of threshold $\mathrm{K}_{\mathrm{th}}$ and smooth specimen endurance, $\sigma_{0}$, one can simply express it as

$\mathrm{k}_{\mathrm{f}}=\left(\sigma_{0} \sqrt{\rho}_{\rho} \mathrm{k}_{\mathrm{t}}^{1.3}\right) /\left(2 \mathrm{~K}_{\mathrm{th}}\right)$

Thus material properties as well as geometry of the notch in terms of $K_{t}$ and $\rho$ are involved in defining the fatigue notch factor. The limiting case of $k_{t}=1$ does not apply here, since the problem is related to crack growth than crack initiation. For $k_{t}=1$, the problem itself reduces to the smooth specimen behavior. Similarly we cannot have a limiting condition of infinite $\rho$ in Eq. 10 since then $\mathrm{k}_{\mathrm{t}}$ becomes 1 reducing the problem again to that of a smooth specimen. Conventionally these limiting conditions are used to check the validity of the empirical equations, since they are developed by insuring that the limiting conditions are applicable.

In contrast to crack propagation, the crack-initiation condition can be related to the peak stress that occurs close to the notch tip. The initiation condition is satisfied, in principle, when $\left(\sigma_{\text {apl }}\right)_{\text {ini }}=\sigma_{0} / \mathrm{k}_{\mathrm{t}}------------11$. 
Thus, Eqs. 7 and 11 define crack initiation and crack propagation conditions for a notched specimen. Since crack propagation not only depends on the magnitude of the stress but also its gradient, non-propagating conditions result when the gradients are too sharp. This happens when $\mathrm{k}_{\mathrm{t}}$ values are high and/or notch tip radii are small. With increasing the notch tip radius the stresses spread out to larger distances. In terms of the Kitagawa-Takahashi diagram, if these distances are larger than $\mathrm{a}_{\mathrm{c}}$, then the initiated crack propagates without arrest. In those cases $\mathrm{k}_{\mathrm{f}}=$ $\mathrm{k}_{\mathrm{t}}$, as has been observed experimentally.

The above equations are expressed in general form in terms of $\sigma_{\text {apl }}$ and $\mathrm{K}_{\mathrm{th}}$. Considering that fatigue is a two-parametric problem with endurance and thresholds being not single-valued but curves, Fig. 2, in applying the equations it is important use the appropriate values for a given Rratio. Hence the endurance and threshold used in the equations should correspond to the specific R-ratios used for the test or application in service. Please note that the developed formulation is valid for fatigue when the stress variables in the equations presented refer to alternating stresses, as well as for monotonic behavior when the stress variables are substituted with maximum stresses from monotonic loads.

In the case of fatigue the authors have identified in previous work on this subject two fundamental material constants or endurances: $\sigma_{\text {max-e }}$ and $\Delta \sigma_{\mathrm{e}}$, respectively defined as endurance maximum stress and range of stress. It is the authors' assumption that both the defined material constants depend only on material and environment and that applied stress maximum and range need to be higher than each endurance stress respectively. These endurances are shown in Figure $2 \mathrm{~b}$ ), and can be obtained by constructing the L-shaped curves from experimental data for fatigue to crack initiation. The equations are presented for maximum stress; however they have to be applied to both maximum stress, as well as stress range in fatigue.

The choice of presenting the equations for maximum stress is not only for synthesis of presentation, but it is justified by observation and analysis of experimental data showing that $\sigma_{\text {max-e }}$ is higher than $\Delta \sigma_{\mathrm{e}}$ for most structural materials. Additionally, the authors consider that Rratios of service stress histories can generally guarantee that when $\sigma_{\text {max-e }}$ threshold is overcome, $\Delta \sigma_{\mathrm{e}}$ is also. For a rigorous analysis it is recommended to apply the developed methodology to both thresholds. In essence one can re-write the above equations in terms of $\Delta \sigma$ endurance and $\Delta \mathrm{K}_{\mathrm{th}}$ thresholds for crack growth.

For the case of monotonic loading the maximum thresholds can be replaced by corresponding fracture mechanics toughness values; failure refers to crack growth instability and continuous growth under the applied stress.

In analyzing the experimental data available in the literature, we follow the above methodology. 


\subsection{Experimental Verification}

We first present the classical data of Frost et $\mathrm{al}^{(1)}$ in terms of propagating and non-propagating cracks from notched specimen in low alloy steel, Fig. 6. We have re-analyzed the data using some of the information provided in their papers in terms of crack lengths, endurance limit and tensile strength of the smooth specimens. The results are plotted in Fig. 7 in terms of log-stress vs log crack length. We have not correlated with the Eq. 8 since the crack growth thresholds are not provided for their material-environmental conditions. Nevertheless, the Fig. 7 shows that the data for all the broken specimen fall on a straight line, thus defining the crack growth condition while all the unbroken specimens data fall on the non-propagating side. The endurance and the tensile strength data also are shown. The material behavior follows closely that of Fig. 4 thus conceptually validating the approach. We now present the analysis of the published data on various materials wherever sufficient information is available for our analysis.

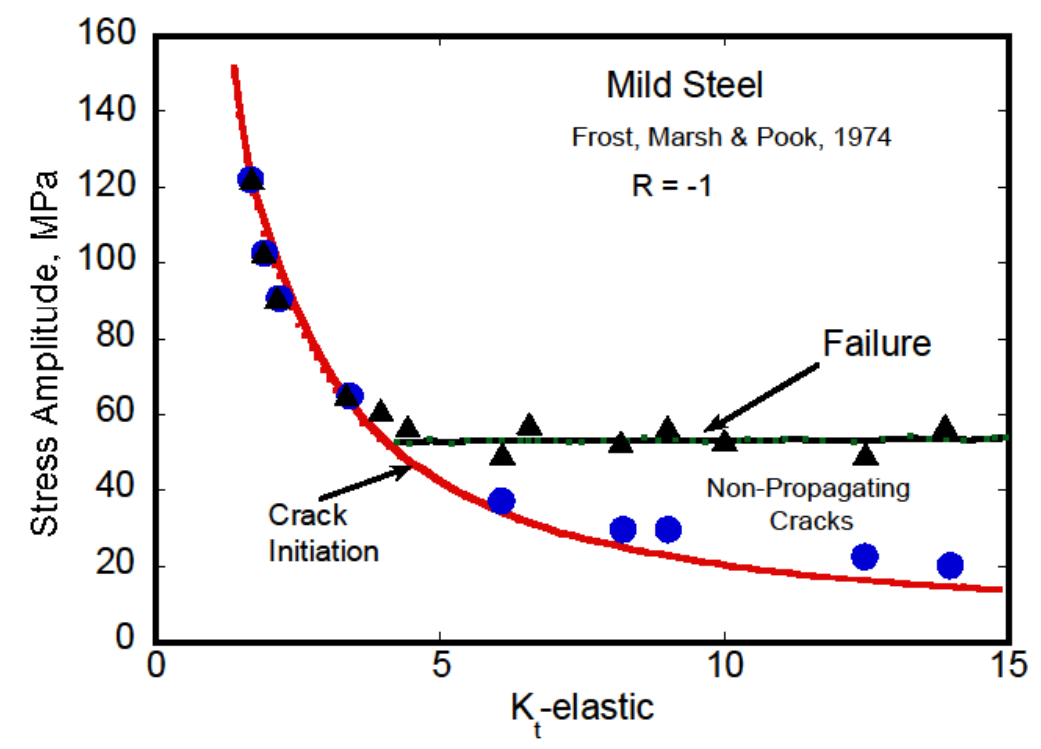

Figure 6: Classical fatigue data of notched specimens in mild steel by Frost et al, as a function of $\mathbf{K}_{\mathrm{t}}$ showing propagating non-propagating conditions. 


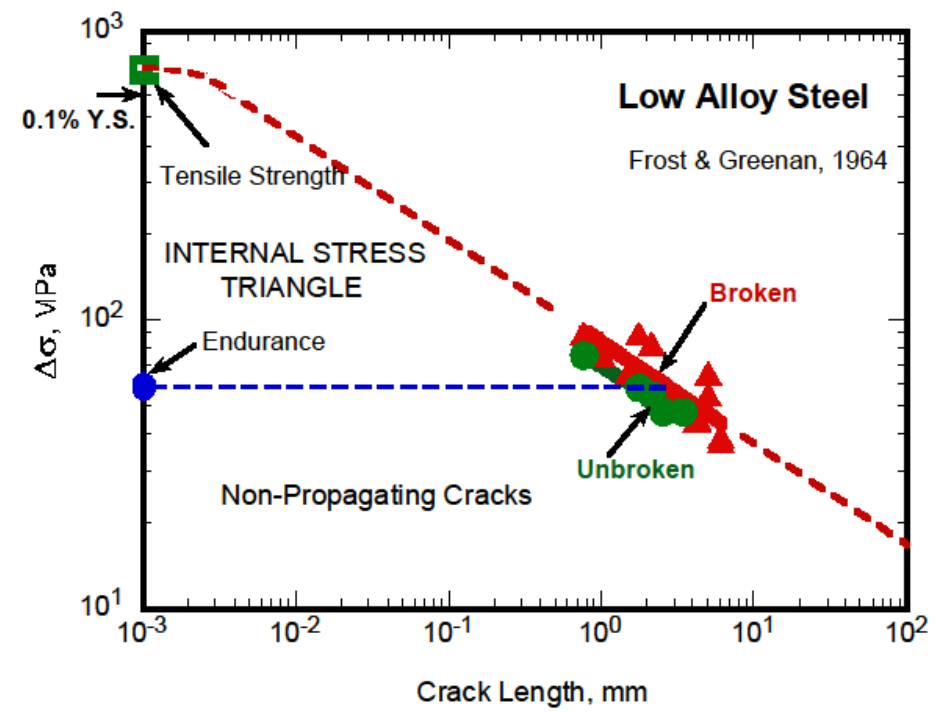

Figure 7: Reanalysis of the data in terms of nominal stress and reported crack lengths. The broken specimens define the propagating line, while unbroken specimens fall below that line. Endurance and tensile strength of smooth specimen are also shown, validating the current approach.

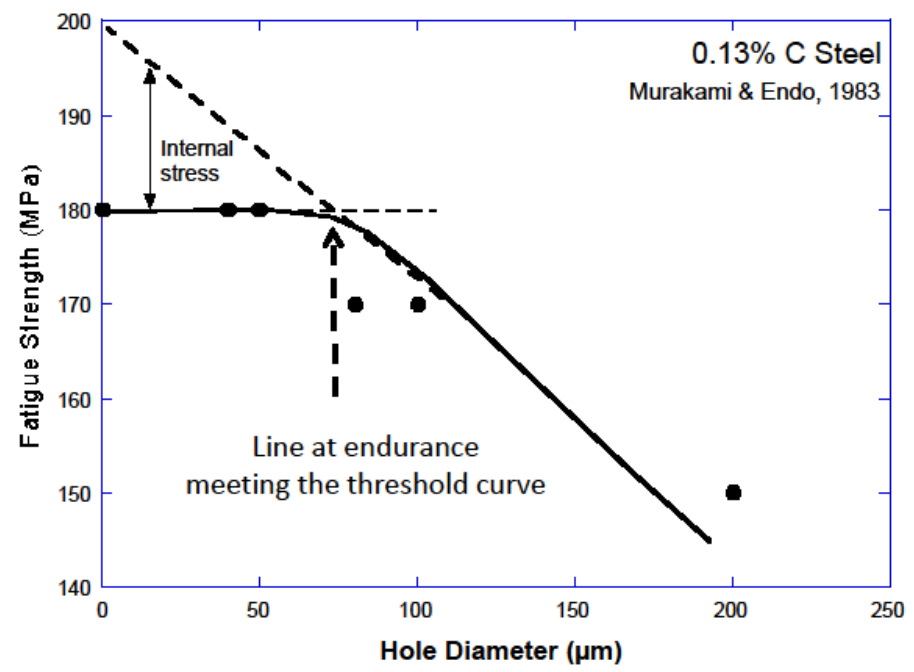

Figure 8: Plotting fatigue strength of specimens with holes (Murakami and Endo's data) showing the behavior depicted by Kitagawa-Takahashi diagram.

\subsection{Analysis of Notch-fatigue data}

Most of the data for different materials has been collected by Liu and Mahadevan ${ }^{(27)}$. Here, since only part of their data is being used, the data are reorganized tabulating only the relevant parameters needed for the computation of conditions for crack initiation and its propagation. 
Tables 1 and 2 provide the data used for the analysis based on the above reference. As general comments, for the computation of the notch fatigue data, only three important experimental values are needed. One is the endurance of the smooth specimen, and second is the crack growth thresholds, and the third is related to notch geometry in terms of the $\mathrm{k}_{\mathrm{t}}$ and $\rho$ values. Since most of the reported tests are done either at $\mathrm{R}=-1$ or $\mathrm{R}=0$, we use the endurance and threshold values at the corresponding R-ratios, without concerning about the R-ratio effects. Since endurance test is based on S-N curve-data of smooth specimens with associated scatter in the data, the reported values may represent some average value. Similarly the crack growth threshold data are based on fracture mechanics tests and require sufficiently low crack growth rates to define the value. Fracture mechanics based thresholds and S-N endurance data of smooth specimens may not necessarily be from the same source. As will be shown below, most of the data for different types of materials follow closely the theoretical predictions. There are couple of exceptions particularly $0.45 \mathrm{C}$ Steel at $\mathrm{R}=-1$ data. Few of the reported values at low $\mathrm{k}_{\mathrm{t}}$ are out of bound, and therefore are rejected considering them as errors in the original data. The data that are out of bound are not shown here. In this particular case, however, most of the data at higher $\mathrm{k}_{\mathrm{t}}$ values appear to be reasonable and therefore are retained. In the case of another material, 2.25 Cr-1 Mo steel, the whole data range gives results completely out of bound. Here the available threshold data of the material could be the cause of the discrepancy. With the exception of these two cases, the rest of the data for many materials follow closely the theoretical predictions.

Another important point to note is that Eq. 7 provides the conditions for crack growth and not necessarily for the specimen failure. On the other hand, the experimental data reported for notchfatigue corresponds to complete failure. Hence to be accurate, one should use $\mathrm{K}_{\mathrm{IC}}$ value in Eq.7 under fatigue, instead of $\mathrm{K}_{\mathrm{th}}$ value used for analysis. Hence, use of the $\mathrm{K}_{\mathrm{th}}$ value implies that the calculated stress value will be the minimum stress needed for crack growth. The actual failure stress values should be equal to or greater than this minimum stress value. The KitagawaTakahashi diagram provides the basis for the use of threshold $\mathrm{K}_{\mathrm{th}}$ rather than the $\mathrm{K}_{\mathrm{IC}}$ value.

Table 1: Notch-Specimens with Holes.

SAE 1045 Steel, $\mathrm{R}=-1, \sigma_{0}=448 \mathrm{MPa}, \mathrm{K}_{\mathrm{th}}=9 \mathrm{MPa} \sqrt{\mathrm{m}}_{\mathrm{m}}$

\begin{tabular}{|c|c|c|c|c|}
\hline $\mathrm{D}, \mathrm{mm}$ & $\rho, \mathrm{mm}$ & $\mathrm{W}, \mathrm{mm}$ & $\mathrm{k}_{\mathrm{t}}$ & Expt. $\sigma_{\mathrm{N}}, \mathrm{MPa}$ \\
\hline 0.120 & 0.120 & 44.45 & 3.0 & 357 \\
\hline 0.250 & 0.250 & 44.45 & 3.0 & 306 \\
\hline 0.50 & 0.50 & 44.45 & 3.01 & 273 \\
\hline 1.50 & 1.50 & 44.45 & 3.02 & 231 \\
\hline 2.5 & 2.5 & 44.45 & 3.04 & 231 \\
\hline
\end{tabular}

SAE 1045 Steel, $\mathrm{R}=0, \sigma_{0}=448 \mathrm{MPa}, \mathrm{K}_{\mathrm{th}}=6.9 \mathrm{MPa} \sqrt{\mathrm{m}}_{\mathrm{m}}$

\begin{tabular}{|c|c|c|c|c|}
\hline $\mathrm{D}, \mathrm{mm}$ & $\rho, \mathrm{mm}$ & $\mathrm{W}, \mathrm{mm}$ & $\mathrm{k}_{\mathrm{t}}$ & Expt. $\sigma_{\mathrm{N}}, \mathrm{MPa}$ \\
\hline 0.120 & 0.120 & 44.45 & 3.0 & 325 \\
\hline
\end{tabular}




\begin{tabular}{|c|c|c|c|c|}
\hline 0.250 & 0.250 & 44.45 & 3.0 & 308 \\
\hline 0.50 & 0.50 & 44.45 & 3.01 & 270 \\
\hline 1.5 & 1.5 & 44.45 & 3.02 & 212 \\
\hline 2.5 & 2.5 & 44.5 & 3.04 & 209 \\
\hline
\end{tabular}

2024-T351 Al alloy $\mathrm{R}=-1, \sigma_{0}=248 \mathrm{MPa}, \mathrm{K}_{\mathrm{th}}=4.4 \mathrm{MPa} \sqrt{\mathrm{m}}$

\begin{tabular}{|c|c|c|c|c|}
\hline $\mathrm{D}, \mathrm{mm}$ & $\rho, \mathrm{mm}$ & $\mathrm{W}, \mathrm{mm}$ & $\mathrm{k}_{\mathrm{t}}$ & Expt. $\sigma_{\mathrm{N}}, \mathrm{MPa}$ \\
\hline 0.120 & 0.120 & 44.45 & 3.0 & 159 \\
\hline 0.250 & 0.250 & 44.45 & 3.0 & 123 \\
\hline 0.50 & 0.50 & 44.45 & 3.0 & 121 \\
\hline 1.5 & 1.5 & 44.45 & 3.0 & 83.8 \\
\hline
\end{tabular}

2024-T351 Al alloy $\mathrm{R}=0, \sigma_{0}=172 \mathrm{MPa}, \mathrm{K}_{\mathrm{th}}=4.0 \mathrm{MPa} \sqrt{\mathrm{m}}$

\begin{tabular}{|c|c|c|c|c|}
\hline $\mathrm{D}, \mathrm{mm}$ & $\rho, \mathrm{mm}$ & $\mathrm{W}, \mathrm{mm}$ & $\mathrm{k}_{\mathrm{t}}$ & Expt. $\sigma_{\mathrm{N}}, \mathrm{MPa}$ \\
\hline 0.120 & 0.120 & 44.45 & 3.0 & 172 \\
\hline 0.250 & 0.250 & 44.45 & 3.0 & 113 \\
\hline 0.50 & 0.50 & 44.45 & 3.01 & 107 \\
\hline 1.5 & 1.5 & 44.45 & 3.02 & 85.8 \\
\hline
\end{tabular}

G40.11 Steel $\mathrm{R}=-1, \sigma_{0}=540 \mathrm{MPa}, \mathrm{K}_{\mathrm{th}}=11.5 \mathrm{MPa} \sqrt{\mathrm{m}}$

\begin{tabular}{|c|c|c|c|c|}
\hline $\mathrm{D}, \mathrm{mm}$ & $\rho, \mathrm{mm}$ & $\mathrm{W}, \mathrm{mm}$ & $\mathrm{k}_{\mathrm{t}}$ & Expt. $\sigma_{\mathrm{N}}, \mathrm{MPa}$ \\
\hline 0.20 & 0.20 & 70.0 & 3.0 & 336 \\
\hline 0.480 & 0.480 & 70.0 & 3.0 & 239 \\
\hline 4.80 & 4.80 & 70.0 & 3.0 & 205 \\
\hline
\end{tabular}

Table 2: Notch-Specimens with Notch-Tip Radius

Annealed 0.45C Steel $\mathrm{R}=-1, \sigma_{0}=582 \mathrm{MPa}, \mathrm{K}_{\mathrm{th}}=8.1 \mathrm{MPa} \sqrt{\mathrm{m}}_{\mathrm{m}}$

\begin{tabular}{|c|c|c|c|c|}
\hline $\mathrm{D}, \mathrm{mm}$ & $\rho, \mathrm{mm}$ & $\mathrm{W}, \mathrm{mm}$ & $\mathrm{k}_{\mathrm{t}}$ & Expt. $\sigma_{\mathrm{N}}, \mathrm{MPa}$ \\
\hline 0.01 & 0.02 & 5.02 & 2.55 & 494 \\
\hline 0.01 & 0.01 & 5.02 & 3.23 & 484 \\
\hline 0.1 & 0.6 & 5.2 & 1.78 & 373 \\
\hline 0.1 & 0.3 & 5.2 & 2.13 & 338 \\
\hline 0.1 & 0.1 & 5.2 & 3.06 & 302 \\
\hline 0.1 & 0.05 & 5.2 & 3.98 & 320 \\
\hline 0.1 & 0.02 & 5.2 & 5.86 & 320 \\
\hline 0.5 & 0.6 & 6.0 & 3.21 & 208 \\
\hline 0.5 & 0.3 & 6.0 & 4.13 & 174 \\
\hline 0.5 & 0.31 & 6.0 & 6.57 & 162 \\
\hline 0.5 & 0.05 & 6.0 & 8.97 & 162 \\
\hline 0.5 & 0.02 & 6.0 & 13.7 & 168 \\
\hline 0.5 & 0.01 & 6.0 & 19.0 & 168 \\
\hline 1.5 & 0.6 & 8.0 & 7.82 & 85.4 \\
\hline 1.5 & 0.3 & 8.0 & 10.3 & 68.4 \\
\hline 1.5 & 0.1 & 8.0 & 16.7 & 61 \\
\hline
\end{tabular}




\begin{tabular}{|c|c|c|c|c|}
\hline 1.5 & 0.05 & 8.0 & 23.2 & 61 \\
\hline 1.5 & 0.02 & 8.0 & 36.0 & 61 \\
\hline 1.5 & 0.01 & 8.0 & 50.4 & 63.5 \\
\hline
\end{tabular}

$0.15 \mathrm{C}$ Mild Steel $\mathrm{R}=-1, \sigma_{0}=420 \mathrm{MPa}, \mathrm{K}_{\mathrm{th}}=12.8 \mathrm{MPa} \sqrt{\mathrm{m}}_{\mathrm{m}}$

\begin{tabular}{|c|c|c|c|c|}
\hline $\mathrm{D}, \mathrm{mm}$ & $\rho, \mathrm{mm}$ & $\mathrm{W}, \mathrm{mm}$ & $\mathrm{k}_{\mathrm{t}}$ & Expt. $\sigma_{\mathrm{N}}, \mathrm{MPa}$ \\
\hline 5.08 & 0.05 & 43 & 24 & 68.8 \\
\hline 5.08 & 0.1 & 43 & 17.1 & 70 \\
\hline 5.08 & 0.13 & 43 & 15.4 & 67.7 \\
\hline 5.08 & 0.25 & 43 & 11.3 & 68.8 \\
\hline 5.08 & 0.64 & 43 & 7.54 & 68.8 \\
\hline 5.08 & 1.27 & 43 & 5.66 & 77 \\
\hline 5.08 & 5.08 & 43 & 3.26 & 121 \\
\hline 5.08 & 0.1 & 64 & 14.9 & 84.1 \\
\hline 5.08 & 0.25 & 64 & 9.75 & 90.9 \\
\hline 5.08 & 0.5 & 64 & 7.25 & 84.1 \\
\hline 5.08 & 1.27 & 64 & 4.75 & 104 \\
\hline 5.08 & 7.62 & 64 & 2.5 & 156 \\
\hline
\end{tabular}

SM41B Steel $\mathrm{R}=-1, \sigma_{0}=326 \mathrm{MPa}, \mathrm{K}_{\mathrm{th}}=12.36 \mathrm{MPa} \sqrt{\mathrm{m}}_{\mathrm{m}}$

\begin{tabular}{|c|c|c|c|c|}
\hline $\mathrm{D}, \mathrm{mm}$ & $\rho, \mathrm{mm}$ & $\mathrm{W}, \mathrm{mm}$ & $\mathrm{k}_{\mathrm{t}}$ & Expt. $\sigma_{\mathrm{N}}, \mathrm{MPa}$ \\
\hline 3.0 & 0.39 & 45 & 6.6 & 104 \\
\hline 3.0 & 0.83 & 45 & 4.88 & 95.3 \\
\hline 3.0 & 3.0 & 45 & 3.0 & 128 \\
\hline
\end{tabular}

Table 3: Ti-6Al-4V Alloy Notch Specimen Data.

$\mathrm{R}=0, \sigma_{0}=600 \mathrm{MPa}, \mathrm{K}_{\mathrm{th}}=4.6 \mathrm{MPa} \sqrt{\mathrm{m}}$, From Lanning et al.

\begin{tabular}{|c|c|c|}
\hline$\rho, \mathrm{mm}$ & $\mathrm{k}_{\mathrm{t}}$ & Expt. $\sigma_{\mathrm{N}}$ \\
\hline 0.33 & 1.97 & 404 \\
\hline 0.33 & 2.72 & 274 \\
\hline 0.127 & 2.85 & 294 \\
\hline 0.203 & 2.86 & 303 \\
\hline 0.127 & 4.04 & 213 \\
\hline
\end{tabular}

$\mathrm{R}=0, \mathrm{R}=0, \sigma_{0}=600 \mathrm{MPa}, \mathrm{K}_{\mathrm{th}}=4.6 \mathrm{MPa} \sqrt{\mathrm{m}}$, From Baragetti et al

\begin{tabular}{|c|c|c|}
\hline$\rho, \mathrm{mm}$ & $\mathrm{k}_{\mathrm{t}}$ & Expt. $\sigma_{\mathrm{N}}$ \\
\hline 0.025 & 18.65 & 87 \\
\hline 0.06 & 13.34 & 75.5 \\
\hline 0.26 & 6.63 & 96.4 \\
\hline 0.45 & 5.17 & 126 \\
\hline 1.5 & 3.10 & 205 \\
\hline
\end{tabular}




\subsection{Specimens with Holes}

Here, we sort out the data collected by Liu and Mahadevan ${ }^{(27)}$ in terms notches with holes versus other types of notches. The data for specimens with holes are more extensive since they are easier to machine and test. Fig. 8 shows, first, that the fatigue strength of specimens with holes, (Murakami and Endo's data ${ }^{(24)}$ ), follow closely the propagating and non-propagating conditions as defined by Kitagawa-Takahashi diagram. Extrapolation of the threshold line is done to define the internal stress regime. Thus, we have propagation and non-propagation conditions defined in terms of the hole-size. Here, hole is treated as a crack, for simplicity, since threshold for crack growth is not reported for the same material-environment conditions.

Figs. 9-13 shows the notch-fatigue data in terms of stress for nucleation, predicted minimum stress needed for propagation, and the experimentally determined endurance limit for the smooth and the notched-specimen for several materials and test conditions. In all these plots, the initiation stress value is given by Eq. 11 where the stress for crack initiation is given by the smooth specimen endurance divided by the $\mathrm{k}_{\mathrm{t}}$ value, which is close to 3 as we are dealing with holes. Since both are constant, the stress for crack initiation is constant for all specimens. Crack propagation stresses computed by Eq. 7 follow a line where the slope is related to the threshold stress for the material. Thus the propagation line defines the minimum stress-condition for the initiated crack to propagate. The experimentally determined endurance values defining stress when the specimens failed should be equal to or greater than the minimum stress needed for propagation, within the experimental scatter. For all materials (Fig. 9-13) the experimentally observed endurance of notched specimens is either close to the line or to the right of the line defining the minimum stress for crack propagation. Any experimental scatter could be attributed to the errors in the threshold or endurance values. When the data points for crack initiation also fall on the line or right side of the line, it implies that for those conditions (holes are big) the stress to initiate a crack and the gradient for crack propagation are sufficient for failure as depicted in Fig. 6. Correspondingly, the endurance values are also not far off from the crack initiation points, as can be seen in many of the figures. 


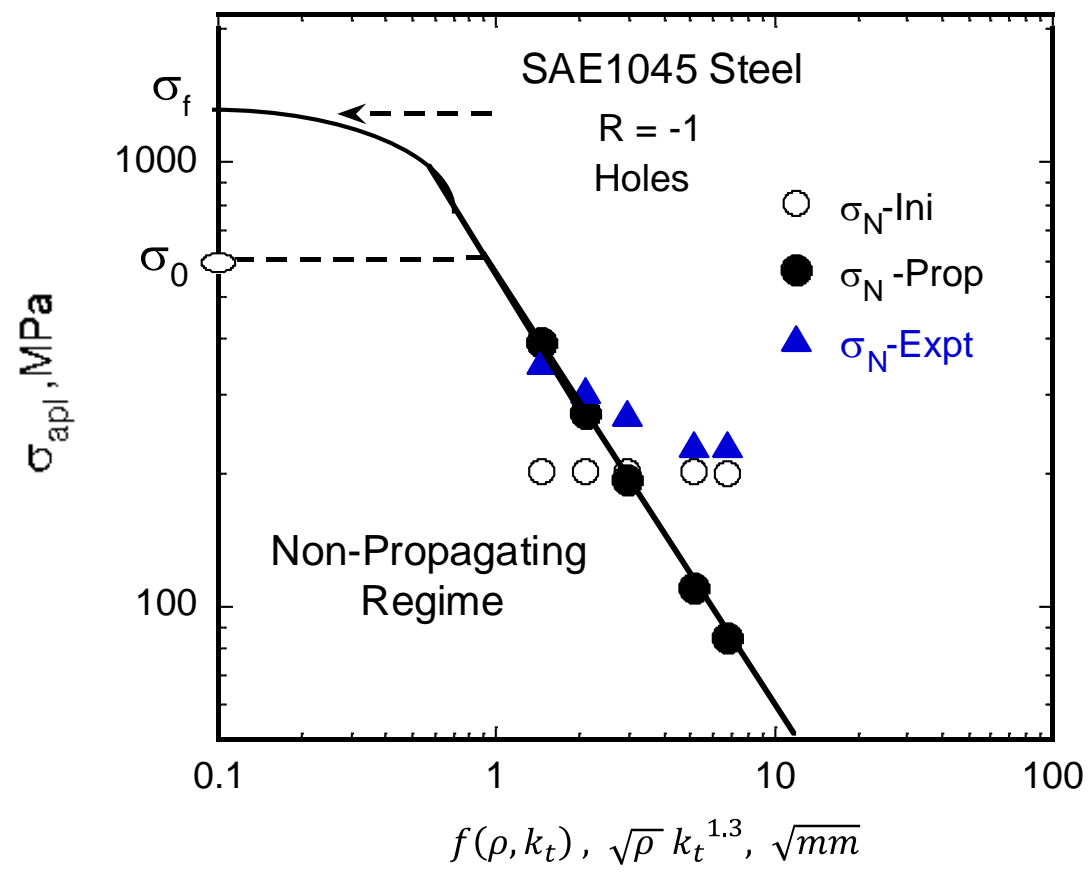

Figure 9: Predicted crack propagation line in relation to experimental crack initiation and fatigue life data for specimens with holes in SAE 1045 Steel at $R=-1$. 


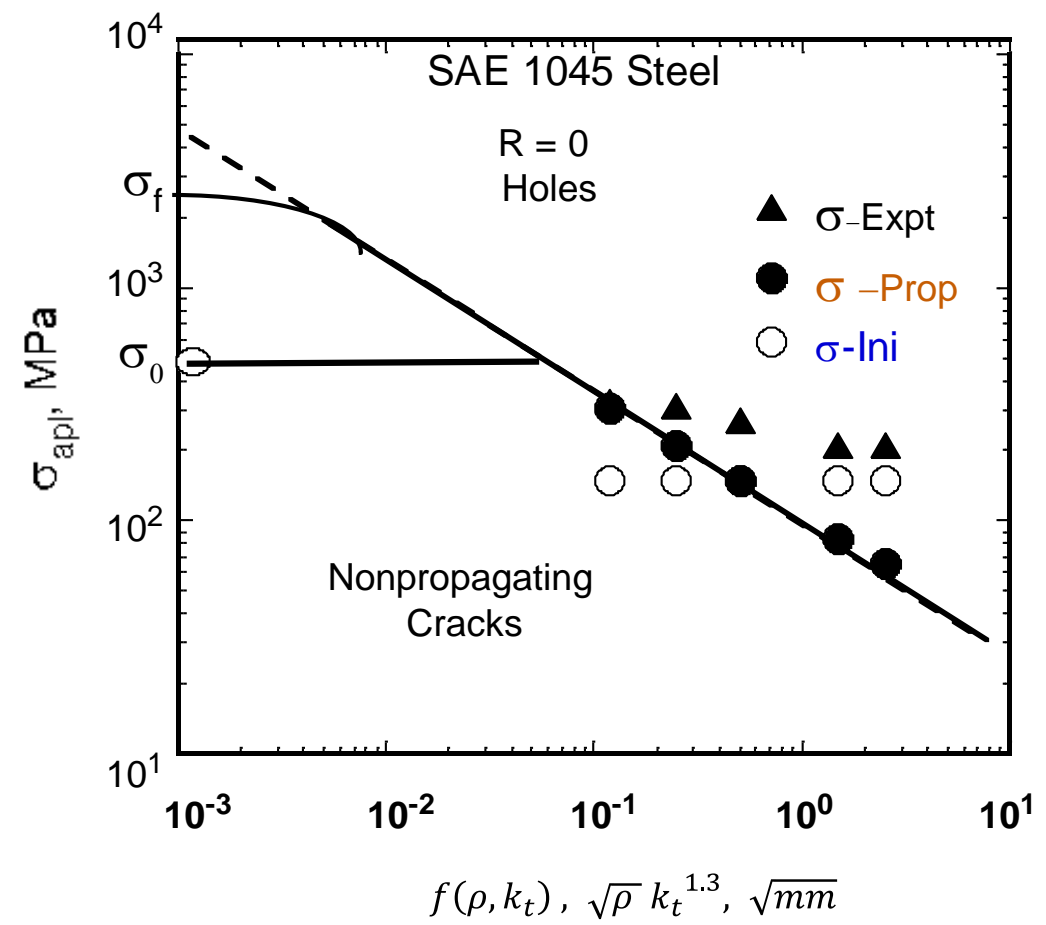

Figure 10: Predicted crack propagation line in relation to experimental crack initiation and fatigue life data for specimens with holes in SAE 1045 Steel at $R=0$.

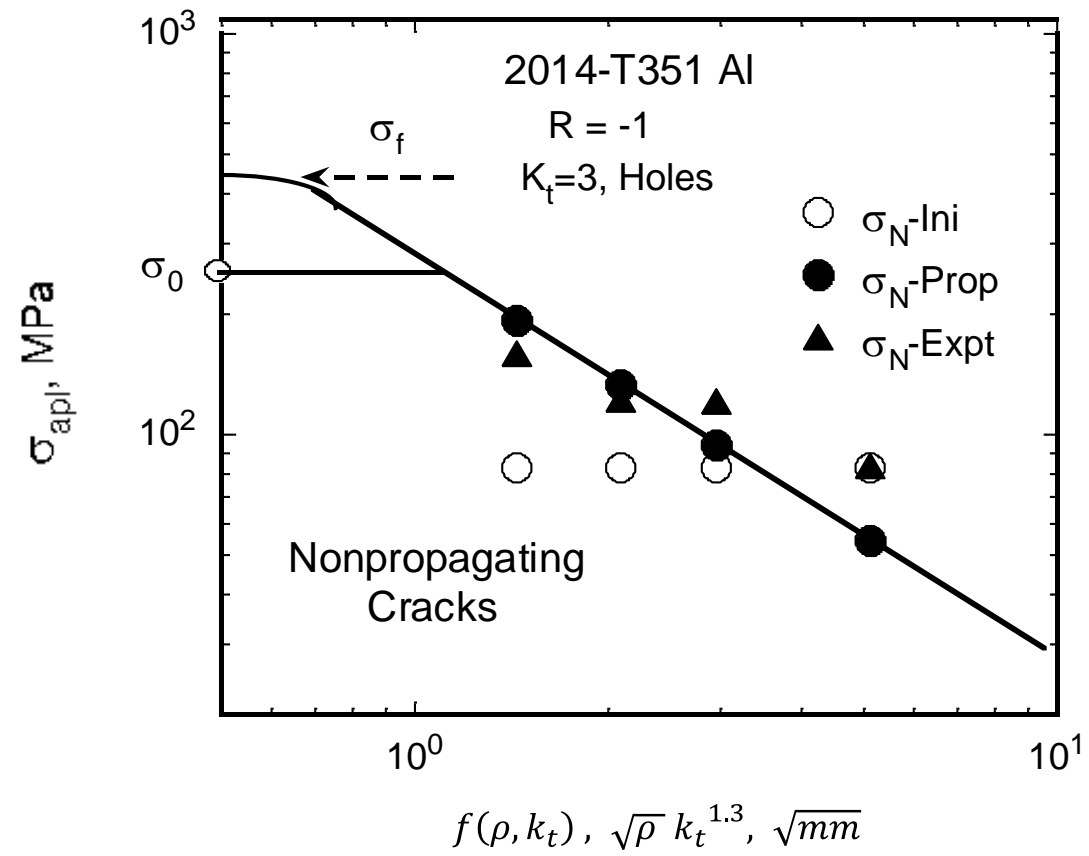

Figure 11: Predicted crack propagation line in relation to experimental crack initiation and fatigue life data for specimens with holes in 2014-T351 Al at $\mathrm{R}=-1$ 


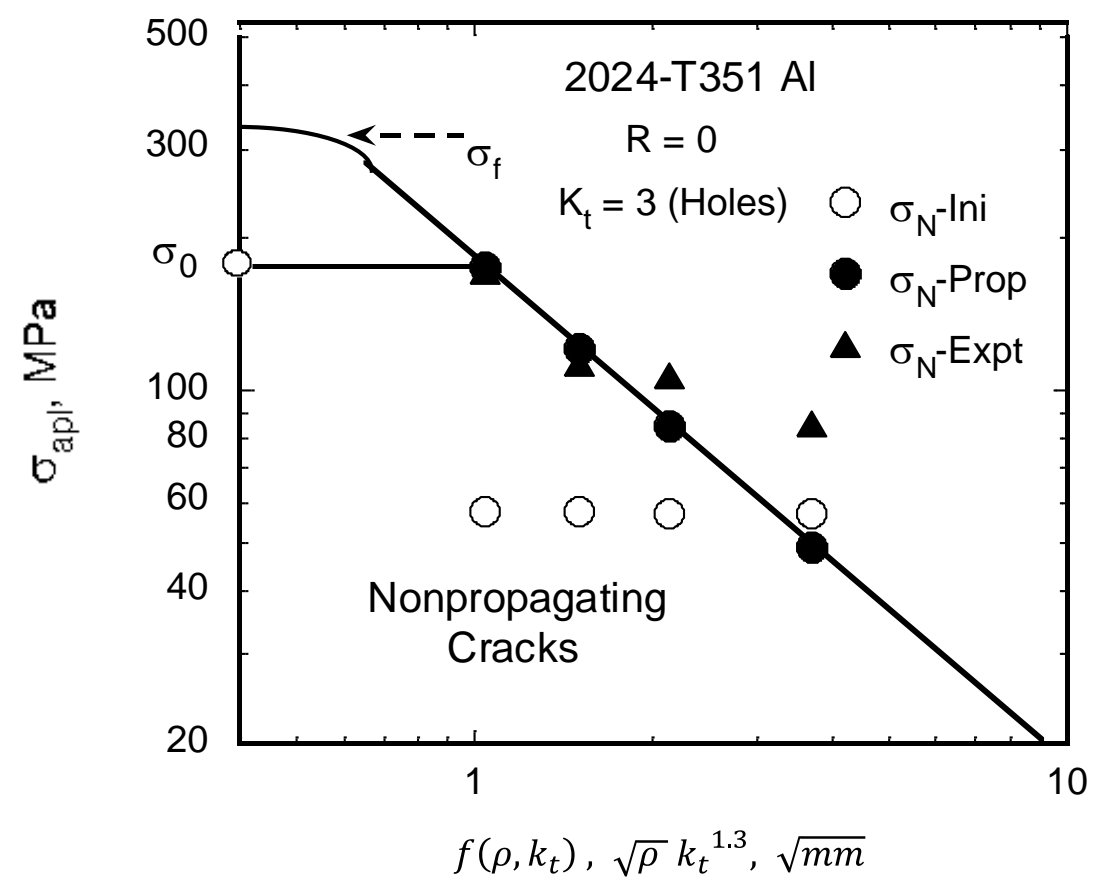

Figure 12: Predicted crack propagation line in relation to experimental crack initiation and fatigue life data for specimens with holes in 2014-T351 Al at $R=0$.

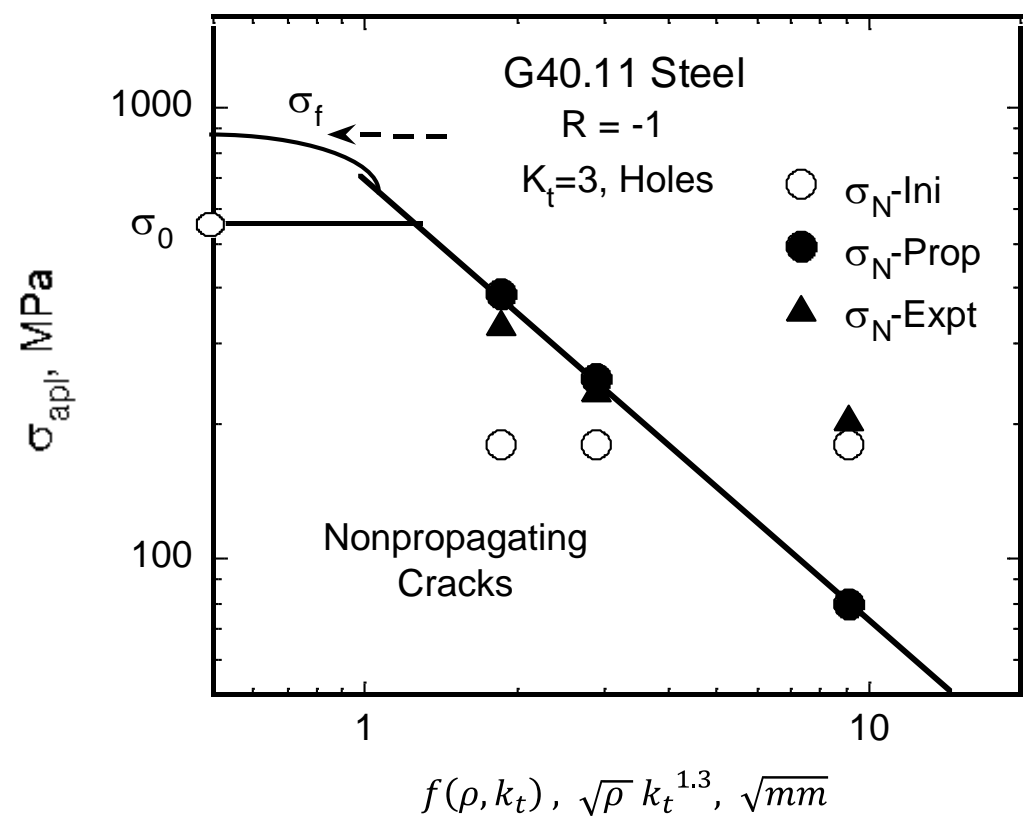

Figure 13: Predicted crack propagation line in relation to experimental crack initiation and fatigue life data for specimens with holes in G40.11 Steel at $R=-1$.

\subsection{Specimens with other types of notches}


Experimental data along with the predicted values for various materials, with different types of notches with varying $K_{t}$ and root radii $\rho$ are shown in Figs. 14-16. The data for 0.45 Steels are extensive and the minimum stress for propagation is well defined. The data for other materials are limited. The experimental endurance data of notched specimens also fall either on the line or to the right of the line as is to be expected. Interestingly, for very small defects the endurance values should be the same as that of the smooth specimen, since defect sizes are less than the critical size from the Kitagawa-Takahashi diagram. The results are in agreement thus validating the Kitagawa-Takahashi diagram and the current predictions. In Fig. 15 for $0.15 \mathrm{C}$ steel all the data correspond to large $\mathrm{k}_{\mathrm{t}}$ values, and plot is magnified in that regime. Hence the plot is too far, at higher end of the $\left\{\vee_{\rho}\left(\mathrm{k}_{\mathrm{t}}\right)^{1.3}\right\}$ value. Endurance of the smooth specimen cannot be shown in this figure. However, the large amount of data presented shows that the predications are accurate for both initiation vs propagation. Non-propagation regime, thus, is clearly defined.

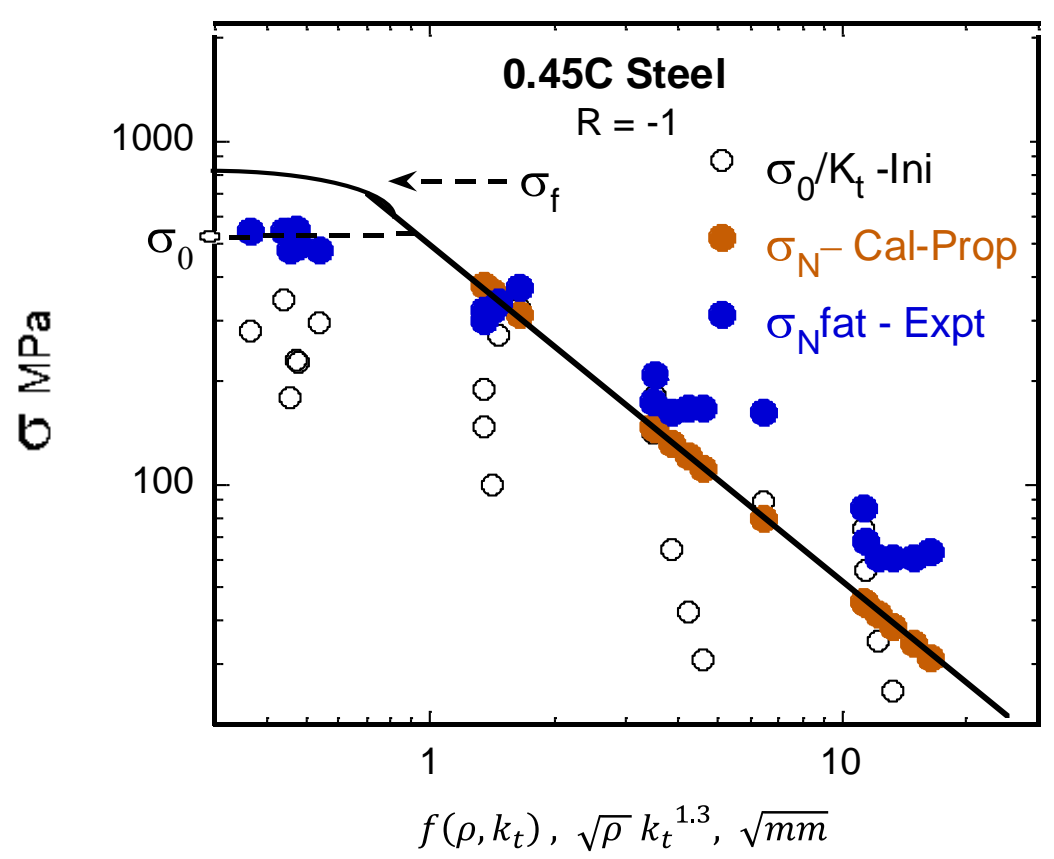

Figure 14: Predicted crack propagation line in relation to experimental crack initiation and fatigue life data for notched specimens in $0.45 \mathrm{C}$ Steel at $R=-1$. 


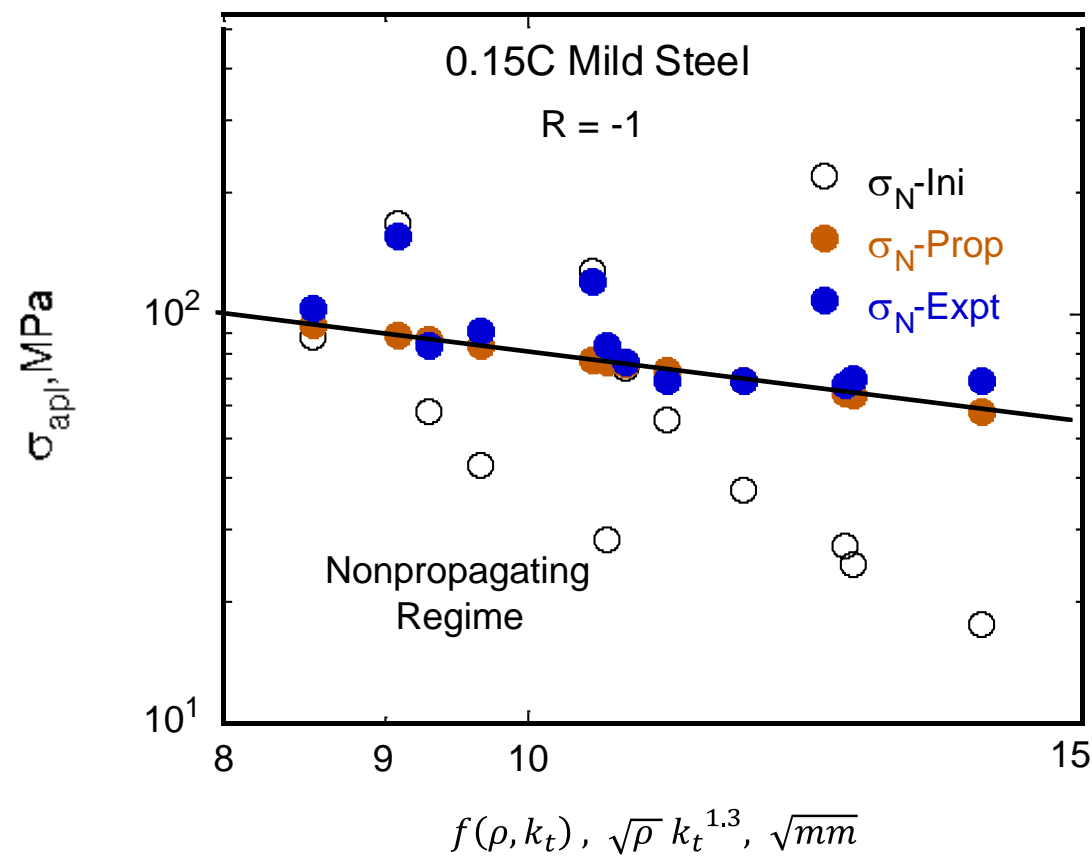

Figure 15: Predicted crack propagation line in relation to experimental crack initiation and fatigue life data for notched specimens in $0.15 C$ Mild Steel at $R=-1$.

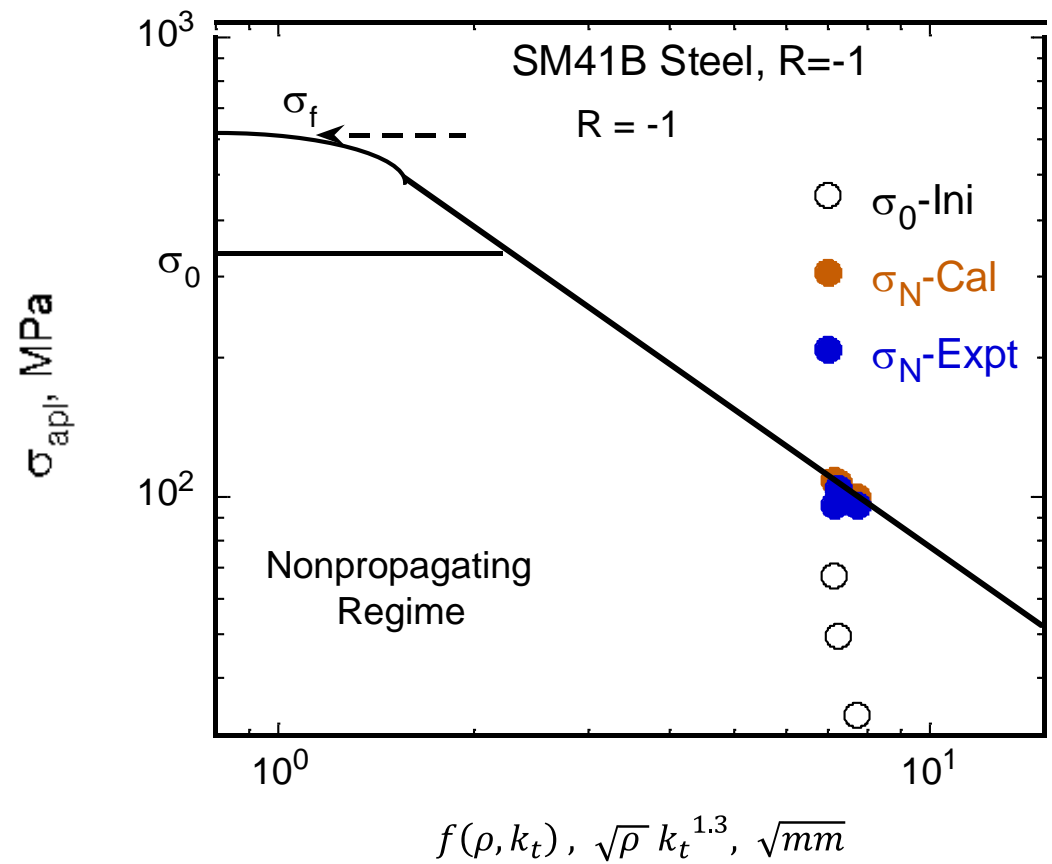

Figure 16: Predicted crack propagation line in relation to experimental crack initiation and fatigue life data for notched specimens in SM41B Steel at $\quad R=-1$. 


\subsection{Ti-6Al-4V alloy data}

We found some fatigue data on notched specimens in Ti-6Al-4V alloy. The first data is from Lanning et $\mathrm{al}^{(20)}$, where they have studied mean stress effects in notched specimens at different $\mathrm{R}$-ratios. We have extracted the data at $\mathrm{R}=0$ and used the fatigue threshold data from Ritchie et $\mathrm{al}^{(28)}$ at $\mathrm{R}=0$ in Eq. 7. Table 3 provides the summary of the data extracted from the above sources. Fig. 16 shows results of our analysis. We have also plotted the fatigue endurance of the smooth specimen, $\sigma_{0}$, as well as its tensile strength, $\sigma_{\mathrm{f}}$. The calculated line is extended by dashed line beyond both the specimen endurance and tensile strength. Analysis shows that at low $\{\sqrt{ } \rho$ $\left.\left(\mathrm{k}_{\mathrm{t}}\right)^{1.3}\right\}$, two of the experimental failure points fell below in the non-propagating regime. We do not know which of the values are in error, since crack growth rate data is extracted from a different source from the fatigue life data. However, the data at high $\left\{\downarrow_{\rho}\left(\mathrm{k}_{\mathrm{t}}\right)^{1.3}\right\}$, both initiation and failure are above the calculated line. These later result are in tune with the analysis, since stress for crack initiation and propagation are above the minimum required for crack propagation. Hence the initiated crack propagates at the imposed stress amplitude without crack arrest, thus causing failure.

We found some additional data on the Ti-6Al-4V alloy reported recently ${ }^{(29)}$. Fig. 17 shows their data and Fig. 18 shows our results. We have again used the same crack growth threshold value from Ritchie et al ${ }^{(28)}$. Fig. 17 shows at low $\mathrm{k}_{\mathrm{t}}$ values both initiation and failure life are very close, and are indistinguishable at the scale of the plot. The two data points at high $\mathrm{k}_{\mathrm{t}}$ value only deviate the initiation-line, Fig. 17. Fig. 18 shows our predicted line in relation to both initiation and propagation. At low value of $\mathrm{k}_{\mathrm{t}}$ both initiation and failure are above the line indicating that a crack initiated will propagate to cause failure. Only for the last two data points in Fig. 17, Fig. 18 shows the stresses for crack initiation are below the propagation line. Hence failure can only occur if the applied stresses are higher. As mentioned before the predicted line only provides the minimum stress required for propagation and failure. The experimental values for failure are above the minimum required. Thus, our analysis correctly predicts the material behavior. We need more systematic experimental data to further validate the analysis. 


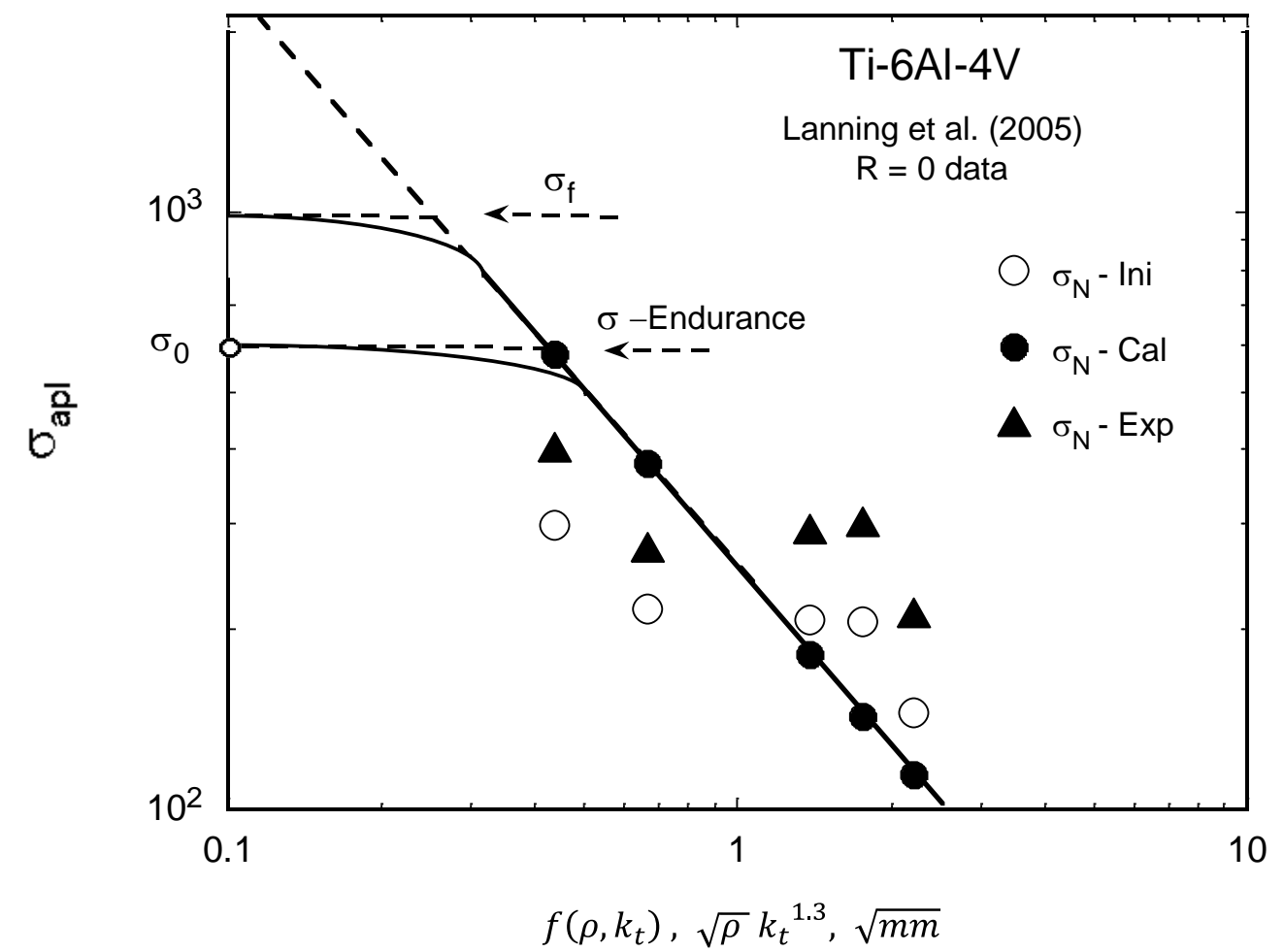

Figure 17: Predicted crack propagation line in relation to experimental crack initiation and fatigue life data for notched specimens in Ti-6Al-4V at $\mathrm{R}=0$.

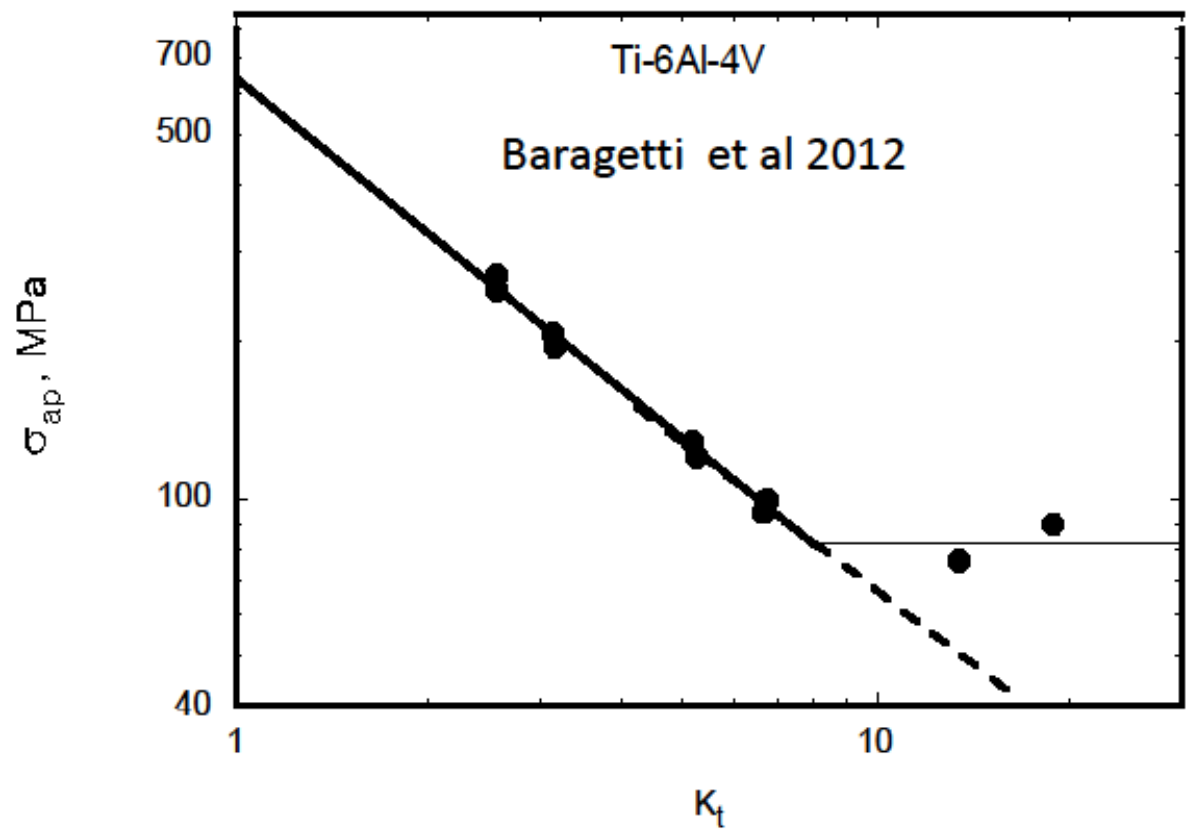

Figure 18: Notch fatigue data in Ti-6Al-4V for various specimens with different $K_{t}$ values. 


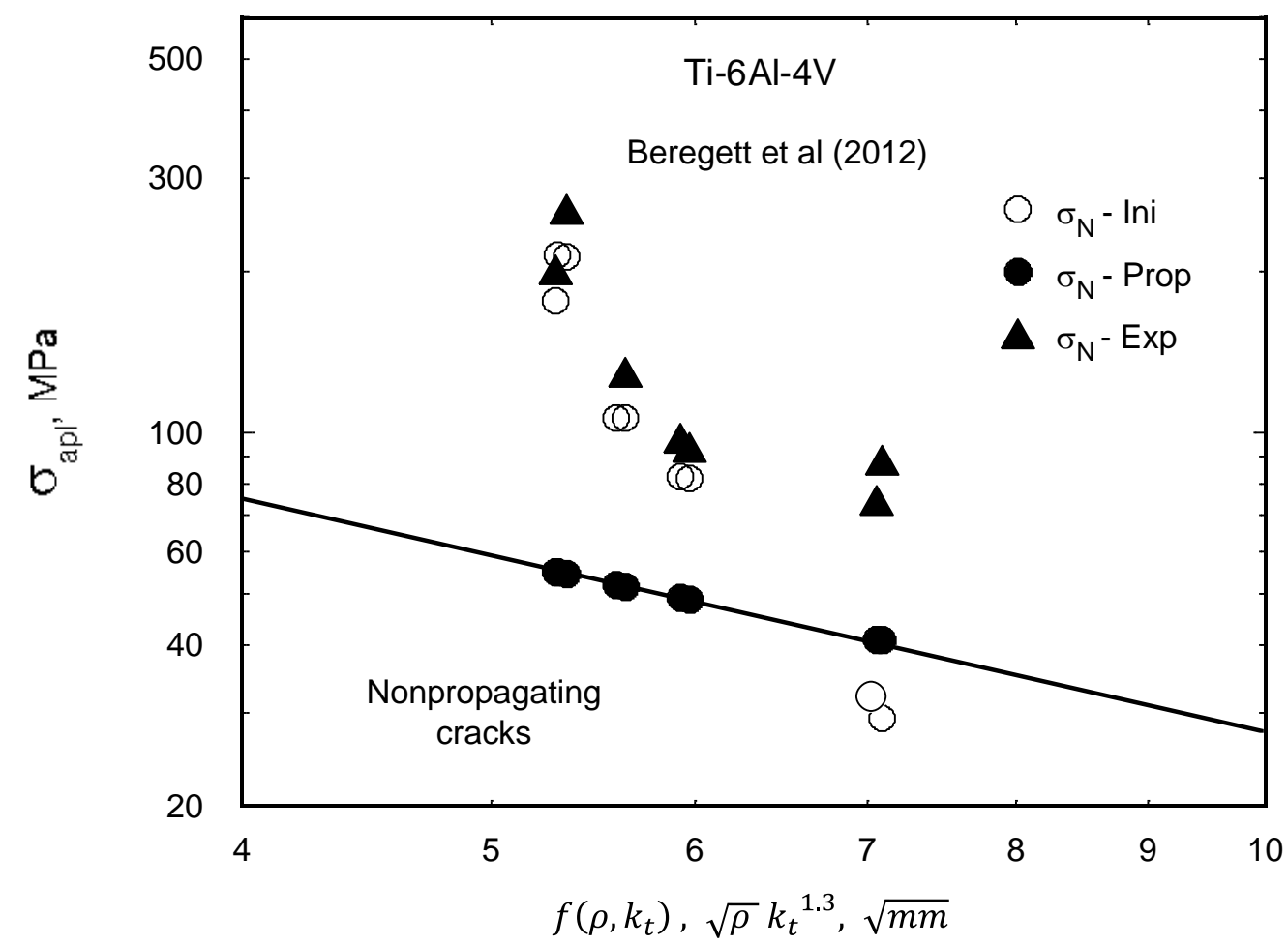

Figure 19: Predicted crack propagation line in relation to experimental crack initiation and fatigue life data for notched specimens in Ti-6Al-4V at $R=0$.

\section{Summary and Conclusions}

The fundamental question for an engineer in service is to know accurately whether a given or an observed crack propagates under the applied loads or not, so that intelligent decision can be made whether the structural component need to be replaced or not. This question is addressed here considering that crack nucleation always occurs at some stress concentrations, whether they are pre-existing or in-situ generated. The strength of the stress concentrations is normally defined by the elastic stress concentration factor $\mathrm{k}_{\mathrm{t}}$ as the ratio of the peek stress to the nominal stress. Since many experiments using notched specimens, particularly under Fatigue, have shown that the fatigue stress concentration factor, $\mathrm{k}_{\mathrm{f}}$, differs from $\mathrm{k}_{\mathrm{t}}$ when $\mathrm{k}_{\mathrm{t}}$ is high, many theories and models have been developed to account for the difference between the two values. Importance of this cannot be overstressed since the prediction of the fatigue life of notched specimen, using the smooth-specimen data, is based on this $\mathrm{k}_{\mathrm{f}}$ value. Most of the models developed to account for the disparity are empirical in nature, and therefore not necessarily accurate. In this paper, we have developed a model based on the elastic-plastic fracture mechanics approach that provides more accurate description of the growth of an incipient crack ahead of a stress concentration. Simple 
equations have been developed based extensive analysis involving various $k_{t}$ values and notch tip radii, $\rho$. The equations correctly predict of the minimum stress required for the continuous growth of the incipient crack thus nucleated.

The application of the developed criteria and methodology to variable amplitude loading is theoretically possible, but complicated by load interaction effects. The authors have envisioned a dynamic Kitagawa-Takahashi diagram able to "expand or contract" as driven by the application of a complex stress histories. A retardation or acceleration model, such as the Unigrow model [30], could be exercised to understand the variation of threshold constants during the application of a variable stress history. Future work in this direction is planned.

The analysis utilizes for life assessment, the endurance limit of smooth specimen, $\sigma_{0}$, elastic stress concentration factor, $\mathrm{k}_{\mathrm{t}}$, and root radius of the notch or a hole, $\rho$, for a given geometry of the component in question, and finally the threshold stress intensity of the material for crack growth. The analysis is based on the Kitagawa-Takahashi diagram which defines the propagating and non-propagating crack-length regimes. In essence, the initiation and propagation conditions for a crack emanated from a notch with $\mathrm{k}_{\mathrm{t}}$ and notch root radius, $\rho$, are given by equations 11 and 7 for fatigue. The analysis, however, is very general and can be applicable for all subcritical crack growth phenomena, since we have shown that the Kitagawa-Takahashi type of flow diagram is valid for all subcritical crack growth processes. For example, for stress corrosion, the corrosion notch stress concentration factor can be defined analogous to the fatigue stress concentration factor, $\mathrm{k}_{\mathrm{f}}$, and equations 7 and 11 can be applied where the threshold stress intensity factor is replaced by $\mathrm{K}_{\mathrm{ISCC}}$, and endurance limit is defined as the failure stress for a smooth specimen under a static load in a given corrosion medium. Validity of this approach for stress corrosion and corrosion fatigue requires extensive experimental data using notch specimens with various $\mathrm{k}_{\mathrm{t}}$ and $\rho$ values, which is lacking.

\section{Acknowledgements}

The authors acknowledge the support of ONR via SBIR contract, TDA N68335-16-C-0135, with Mr. William Nickerson as the technical point of contact.

\section{References}

1. N.E. Frost, K. J. Marsh, L.P. Pook, Metal Fatigue, Dover Publications Inc., New York, NY, 1974, P. 154

2. N.E. Frost, Non-propagating cracks in V-notched Specimens subjected to Fatigue Loading, Aeronotical Quarterly, London, Royal Society, Vo. 8, 1957, pp 1-19. 
3. Neuber, H., Theory of Notches, Published by J.S. Edwards, Ann Arbor, Michigan, 1946

4. R.A.Smith and K. J. Miller, 1977, Fatigue cracks at Notches, J. Mech. Sci, 1977, Vol. 19, pp. $11-22$.

5. R.A. Smith and K. J.Miller, 1977, Prediction of Fatigue Regimes in Notched Components, J. Mech. Sci., Vol. 20, pp. 201-206

6. N. E. Dowling, 1979, Notched member Fatigue life predictions combining crack initiation and propagation, Fatigue of Engineering Materials and Structures, Vo. 2, 129-138.

7. D.L. DuQuesnay, T.H. Topper and M.T. Yu, The effect of Notch Radius on the Fatigue Notch Factor and the propagation of Short Cracks, in Behavior of Short Fatigue Cracks, EGF Pub. 1 Ed. K. J. Miller and E.R. de los Rois, Mechanical Engineering Publication, London, 1986, pp. $323-335$.

8. M.M Hammouda, R.A. Smith, K.J. Miller, Elastic-Plastic fracture mechanics for initiation and propagation of notch fatigue cracks, Fatigue of Engng. Mater. Structures, 1979, 2, 139-154.

9. M.H. El Haddad, T.H. Topper and K.N. Smith, Prediction of non-propagating cracks, Engrg. Frac Mech, 1979, 11, 573-584.

10. M.H. El Haddad, T.HTopper, T.N. Topper, Fatigue life predictions of smooth and notch specimens based on Fracture Mechanics, J. Eng. Mat. Tech, 1981, 103, 91-96

11. N A. Fleck et al, The effect of hole size upon the strength of metallic and polymer foams, J. Mech. Phys. Solids, 2001, 49, 2015-30

12. B. Atzori, P. Lazzarin, G. Meneghetti, Fracture Mechanics and Notch Sensitivity, Fatigue and Fracture Engng Mater Struct A 2003, 26,257-67

13. D. Taylor, Geometrical effects in Fatigue; A unified theoretical model, Int J Fatigue 1999, 21, 413-20

14. D. Taylor, Theory of Critical Distance, Eng. Frac. Mech, 2008, vol. 75, 1696-705

15. W. Yao, K. Xia, Y. Gu, 'On the fatigue notch factor $\mathrm{K}_{\mathrm{f}}$ ', Int. J. Fatigue, 1995, 17,245-51.

16. K. Sadananda, K. Solanki and A.K. Vasudevan, "Subcritical Crack Growth and Crack Tip Driving Forces in Relation to Material Resistance", Corrosion Review, Submitted for publication, 2016.

17. S. Suresh, Fatigue Of Materials, $2^{\text {nd }}$ Edition, 1998 Cambridge University Press, Cambridge.

18. K. Sadananda, S. Sarkar, D. Kajawsaki and A.K. Vasudevan, "A Two Parameter Analysis of S-N Fatigue Life using $\Delta \sigma$ and $\sigma_{\max }$ ”, Int. J. of Fatigue, 2009, Vol. 31, p.1648. 
19. H. Kitagawa, S. Takahashi, Applicability of Fracture Mechanics Specimen to very small cracks or cracks in early stage, in Proc. Of the $2^{\text {nd }}$ Int. Conf. On Mechanical Behavior of Materials, OH, USA,ASM International. 1976.

20. D. B. Lanning, T. Nicholas, G.K. Haritos, On the Critical Distance Theories for the Prediction of the High Cycle Fatigue Limit Stress in Notched Ti-6Al-4V, Int. J. of Fatigue, 2005, 27, 45-57.

21. A. K. Vasudevan, K. Sadananda and N. Louat, "Critical Evaluation Of Crack Closure And Fatigue Crack Thresholds", Mat. Sci. \& Engrg. 1993

22. R.E. Peterson, Notch-Sensitivity, in G. Sines, JL Waisman, Eds. Metal Fatigue, New York, McGraw-Hill, 1959, p. 293-306

23. M. Endo, A.J. McEvily, "An Analysis of the Fatigue Strength of Metals Containing Small Defects", Key Engineering Materials, Vols. 353-358, pp. 323-326, 2007

24.Y.Murakami and M. Endo, Effects of small defects on the fatigue strength of hard steels, in proc. Int. Con. Fatigue, 1981, Materials Experimentation and Design, Warwick Uni. 1981, pp. $431-440$

25. N. Louat, K. Sadananda, A.K. Vasudevan, "A Theoretical Evaluation Of Crack Closure", Met. Trans., Vol.24, pp. 2225-2232, 1993.

26. K. Sadananda, S. Sarkar, Modified Kitagawa Diagram and Transition from Crack Nucleation to Crack Propagation, Met. Mat. Trans. A, 2013, Vol 44, pp 1175-1189

27. Y. Liu and S. Mahadevan, Fatigue limit prediction, of notched components using short crack growth theory and an asymptotic interpolation method, Engineering Fracture Mechanics, Vol. 76, PP 2317-2331, 2009

28. R.O. Richie, D.L. Davidson, B.L. Boyce, J.P. Campbell and O. Roder, High Cycle Fatigue of Ti-6al-4V, Fatigue and Fracture of Engineering Materials and structures, 22, pp. 621-631, 1999.

29. S. Baragetti, S. Calalleri, and F. Tordini, Fatigue Behavior of Notched Ti-6Al-4V in Inert Environment, Key Engineering Materials Volumes, 488-489, 2012, pp. 502-505.

30. S. Mikheevskiy, S. Bogdanov, G. Glinka, Analysis of fatigue crack growth under spectrum loading - The UniGrow fatigue crack growth model (2015) Theoretical and Applied Fracture Mechanics, 79, art. no. 1605, pp. 25-33. 